\title{
Rice Pest Constraints in Tropical Asia: Quantification of Yield Losses Due to Rice Pests in a Range of Production Situations
}

\author{
Serge Savary and Laetitia Willocquet, ORSTOM-IRRI Project on Rice Pest Characterization, International Rice \\ Research Institute, MCPO Box 3127, Makati City 1271, Philippines; Francisco A. Elazegui, Nancy P. Castilla, \\ and Paul S. Teng, IRRI, Entomology and Plant Pathology Division, Philippines
}

\begin{abstract}
Savary, S., Willocquet, L., Elazegui, F. A., Castilla, N. P., and Teng, P. S. 2000. Rice pest constraints in tropical Asia: Quantification of yield losses due to rice pests in a range of production situations. Plant Dis. 84:357-369.

A series of experiments was conducted where a range of injuries due to rice pests (pathogens, insects, and weeds) was manipulated simultaneously with a range of production factors (fertilizer input, water supply, crop establishment method, variety) in different seasons and years. These factors were chosen to represent lowland rice production situations characterized in surveys conducted in tropical Asia and their corresponding range of attainable yield. Experiments complemented one another in exploring the response surface of rice yields to yield-limiting and yield-reducing factors. The resulting experimental data base consisted of 445 individual plots and involved 11 manipulated injuries in a range of attainable yields of 2 to $11 \mathrm{t} \mathrm{ha}^{-1}$. A first, nonparametric, multivariate analysis led to a hierarchy of potential injuries, from marginally (e.g., bacterial leaf blight) to extremely harmful (e.g., rice tungro disease). A second, parametric, multivariate approach resulted in a multiple regression model involving factors generated by principal component analysis on injuries that adequately described the variation in actual yield. One major finding was that some (attainable yield $\times$ injury factors) interactions significantly contributed to the description of variation in actual yield, indicating that some injuries (or their combinations) had a stronger or weaker yield-reducing effect, depending on the level of attainable yield. For instance, yield losses due to sheath blight, weed infestation, and rice tungro disease tend to increase, remain stable, and decrease, respectively, with increasing attainable yields. Back-computations using the principal component regression model estimated yield losses caused by individual injuries, using the mean injury levels in a population of farmers' fields surveyed across tropical Asia. The results indicate that sheath blight, brown spot, and leaf blast are diseases that cause important losses (between 1 and 10\%) regionally. Among the insect injuries, only white heads caused by stem borers appear of relevance ( $2.3 \%$ yield losses). These injuries, however, do not match in importance those caused by weeds, whether outgrowing the rice crop canopy (WA) or not (WB), both types of injuries causing about $20 \%$ yield losses when considered individually. When all mean injuries were combined into one mean injury profile occurring at a regional attainable yield of $5.5 \mathrm{t} \mathrm{ha}^{-1}$, a mean yield loss of $37.2 \%$ was estimated, indicating that injuries were less than additive in their yield-reducing effects. Scenario analyses were conducted in a set of (production situations $\times$ injury profiles) combinations characterized from surveys in farmers' fields in tropical Asia. Depending on the scenario chosen, losses ranging from 24 to $41 \%$ were found.
\end{abstract}

Additional keywords: multiple pest system, yield loss assessment, yield loss experiment

Analysis of yield losses due to crop pests (pathogens, insects, or weeds) has become a diverse research domain (25), building upon landmark publications

Corresponding author: Serge Savary

E-mail: Serge.Savary@mpl.ird.fr

Current address of L. Willocquet: IRD, Institut de Recherche pour le Développement (formerly ORSTOM), 911 Ave. Agropolis BP 5045, 34032 Montpellier cedex, France.

Accepted for publication 5 November 1999.

Publication no. D-2000-0105-02S

(C) 2000 The American Phytopathological Society especially when injuries due to pests are high. As a result, a biased perspective is offered to the public (whether scientific or not) where (i) pesticides are efficient, and (ii) pests always cause yield losses, sometimes under unrealistic conditions.

Quantitative information on yield losses due to pests is vital to the development of sound plant protection management practices. It is therefore surprising to see how limited our information is today in the particular case of rice-the most important food crop worldwide $(14,26,50,52)$. The information currently available on yield losses due to rice pests is extremely heterogeneous with respect to assessment methods, production situations, and injuries (52). The sources of information are diverse, too, and the representativeness of this information has to be questioned (42). This situation is due to a number of reasons, among which is the extreme diversity of environments and cropping practices associated with rice production, as well as the wide array of harmful organisms affecting rice crops. A first objective of this study was to generate information standardized in format and homogeneous in representativeness for lowland rice in tropical Asia.

Following the theory of production ecology $(35,56)$, three production levels (potential, attainable, and actual) may be distinguished in any production situation (the combination of production factors influencing agricultural production, from physical to socioeconomic: 10). Yield-defining, -limiting, and -reducing factors determine the potential, attainable, and actual yield levels, respectively. Quantification of yield loss requires that measurements of attainable yield (i.e., the yield output of a crop that did not suffer injuries from pests) are made $(36,47,48)$. Measurement of attainable yield is next to impossible under farmer's field conditions. Measurement of both attainable and actual yield, so that the gap-yield loss due to pest injury-is measured, implies experimentation. A second objective was to develop a data base derived from a chain of yield-loss experiments using a standardized protocol (39).

Two types of interactions are important to consider in multiple-injury yield-loss 
studies. Interactions may first occur among injuries in their yield-reducing effects $(17,18)$. Interactions may also occur between injuries and attainable yield, i.e., the same level of injury may lead to different losses depending on production situations; conversely, the same level of loss may be caused by different levels of a given injury depending on production situations $(40,48)$. The experiments should thus cover a wide range of attainable yields, as well as a wide range of each of the considered injuries (alone or in combination) in order to address these interactions. A third objective of this study was to quantify yield losses due to varying levels of injuries caused by rice pests, considering a range of attainable yields.

A characterization study based on survey data $(41,45)$ determined the links between production situations (represented by a set of patterns of cropping practices and associated to a given attainable yield), injury profiles (combinations of injuries due to rice pests in a crop cycle), and actual rice yields in farmers' fields across Asia. The experimental data base reported here complements these survey data. A fourth objective of this work was to link survey and yield-loss data in order to quantify current constraints due to rice pests in a range of rice production situations, and to provide a quantitative background to set priorities for rice pest management in tropical Asia.
MATERIALS AND METHODS

Concepts and operational definitions. A given pest (whose population may vary over time) may lead to the appearance of injuries in a crop, which may in turn result in damage (yield loss; 57) as it interferes with the physiological processes of crop growth and yield accumulation. The function that relates injury and damage was termed a damage function (57). This study focuses on damage functions in a multivariate space defined by variations of (i) the environmental conditions under which yield builds up, and (ii) injury levels due to several pests, considered solely or in combination. Many organisms are potentially harmful to rice. Conversely, rice is grown under an extremely wide range of environments in tropical Asia $(28,45,52,53)$. Empirical models have been derived to estimate damage for a number of individual rice pests $(52,55)$. However, a farmer's rice crop does not usually experience only one injury during its cycle. More frequently, several injuries occur, in sequence or simultaneously. Analyzing survey data showed that these injuries usually do not occur independently, but as sets: "injury profiles" $(38,39,45)$. Further analysis indicated that these injury profiles, as well as variation in actual yield, were strongly linked with patterns of cropping practices (45).
Development of the yield loss experimental data base. An approach (45) to address combinations of injuries and patterns of cropping practices (which correspond to given production situations and attainable yields) and their effects on rice yield variation was thus developed. As many injury combinations as possible had to be considered in the widest possible range of production patterns, resulting in a very large number of treatments. A chain of factorial, unreplicated experiments was established in farmers' fields and at the IRRI Research Farm from the dry season of 1991 until the dry season of 1995 . The concept of yield response surface $(49,54)$ was used to specify the objectives of each experiment: each one was devised in turn to explore a given sector of the rice yield response surface to variable inputs (yieldlimiting factors) and injuries (yield-reducing factors). The yield-limiting factors that were manipulated (Table 1) during the experiments included the amount of water supplied to the crop and the amount and regime of fertilizer (mostly nitrogen) input. Varieties with differing potential yields and different crop establishment methods were also used as factors. These factors were considered during the succession of seasons (rainy and dry) corresponding to large variations in radiation intercepted by the crop canopy.

Table 1. Features of successive experiments involved in the development of a yield loss data base for tropical lowland rice

\begin{tabular}{|c|c|c|c|c|c|c|c|c|c|c|c|c|c|c|c|c|c|}
\hline \multirow{3}{*}{$\begin{array}{l}\text { Experi- } \\
\text { ment }^{\text {b }}\end{array}$} & \multirow[b]{3}{*}{ Year } & \multirow[b]{3}{*}{ Season $^{\mathrm{c}}$} & \multicolumn{4}{|c|}{ Production factors } & \multirow{2}{*}{\multicolumn{11}{|c|}{ Injuries $^{\mathrm{a}}$}} \\
\hline & & & & & & Crop & & & & & & & & & & & \\
\hline & & & Variety $^{\mathbf{d}}$ & Fertilizer $^{\mathbf{e}}$ & Irrigation $^{f}$ & est.g & BLB & SHB & RTD & BS & DH & WH & WM & LB & NB & WA & WB \\
\hline FF1 & 1991 & D & V1 & FE3 & W3 & TR & $\mathrm{X}$ & $X$ & & & $X$ & & & & & $X$ & $X$ \\
\hline FF2 & 1992 & $\mathrm{R}$ & $\mathrm{V} 1, \mathrm{~V} 2$ & FE0, FE3 & W3 & TR & $X$ & $\mathrm{X}$ & & & $X$ & & & & & $X$ & $X$ \\
\hline FF3 & 1992 & D & V2 & FE3 & W3 & $\mathrm{TR}$ & $\mathrm{X}$ & $\mathrm{X}$ & & & $X$ & & & & & $\mathrm{X}$ & $X$ \\
\hline IRRI1 & 1992 & $\mathrm{R}$ & V5 & FE10 & W3 & TR & & $\mathrm{X}$ & & & & & & $\mathrm{X}$ & $X$ & & \\
\hline IRRI2 & 1993 & $\mathrm{R}$ & $\begin{array}{l}\text { V2, V3, } \\
\text { V4 }\end{array}$ & FE2,FE9 & W3 & $\mathrm{TR}$ & $\mathrm{X}$ & $X$ & & & & & $X$ & & & & \\
\hline IRRI3 & 1993 & $\mathrm{D}$ & $\begin{array}{l}\text { V2, V3, } \\
\text { V4 }\end{array}$ & FE1, FE7 & W3 & TR & $\mathrm{X}$ & $\mathrm{X}$ & & & & & $X$ & & & & \\
\hline IRRI4 & 1993 & $\mathrm{D}$ & $\mathrm{V} 2$ & FE3 & $\begin{array}{l}\text { W1, W2, } \\
\text { W3 }\end{array}$ & TR, DS & & $\mathrm{X}$ & & & & $X$ & & & & $X$ & \\
\hline IRRI5 & 1994 & $\mathrm{R}$ & V3 & FE0, FE6 & $\begin{array}{l}\text { W1, W2, } \\
\text { W3 }\end{array}$ & TR & & & $X$ & & & $X$ & & & & $\mathrm{X}$ & \\
\hline IRRI6 & 1994 & $\mathrm{D}$ & V3 & FE4 & $\begin{array}{l}\text { W1, W2, } \\
\text { W3 }\end{array}$ & TR, DS & & & $\mathrm{X}$ & & $X$ & & $X$ & & & & \\
\hline IRRI7 & 1995 & $\mathrm{R}$ & V4 & FE0, FE7 & $\begin{array}{l}\text { W1, W2, } \\
\text { W3 }\end{array}$ & TR, DS & & $\mathrm{X}$ & & & $\mathrm{X}$ & & & & & & $X$ \\
\hline IRRI8 & 1995 & $\mathrm{D}$ & V5 & $\begin{array}{l}\text { FE0, FE5, } \\
\text { FE8 }\end{array}$ & W2, W3 & TR & & & & & $\mathrm{X}$ & & & & & $X$ & $X$ \\
\hline
\end{tabular}

a BLB: bacterial leaf blight (Xanthomonas campestris pv. oryzae); SHB: sheath blight (Rhizoctonia solani); RTD: rice tungro disease; BS: brown spot (Cochliobolus miyabeanus); DH: dead hearts (stem borers, Scirpophaga incertulas); WH: white heads (stem borers, S. incertulas); WM: whorl maggot (Hydrellia philippina); LB: leaf blast (Pyricularia oryzae); NB: neck blast (P. oryzae); WA: weed infestation above the rice crop canopy; WB: weed infestation below the rice crop canopy. $\mathrm{X}$ indicates that the corresponding injury was part of the (subplot) treatments.

${ }^{b}$ FF: farmer's field experiment, IRRI: experiment at the IRRI research farm.

${ }^{c}$ D: dry season; R: rainy season.

d V1: PSBRc4; V2: C4-137; V3: IR64; V4: IR74; V5: IR72.

${ }^{\mathrm{e}}$ Fertilizer applications in kg N-P-K ha ${ }^{-1}$ : FE0: no fertilizer application; FE1: fertilizer application at seedling stage (25-0-0); FE2: fertilizer application at panicle initiation (30-0-0); FE3: fertilizer application at seedling stage (100-0-0); FE4: fertilizer application at seedling stage (120-0-0); FE5: fertilizer application at seedling stage (30-0-0) and at panicle initiation (30-0-0); FE6: fertilizer application at seedling stage (30-0-0), at panicle initiation (50-0-0), and at flowering stage (30-0-0); FE7: fertilizer application at seedling stage (40-0-0), at panicle initiation (50-0-0), and at flowering stage (45-0-0); FE8: fertilizer application at seedling stage (50-0-0), at tillering stage (50-0-0), and at panicle initiation (50-0-0); FE9: fertilizer application at seedling stage (100-30-30) and at panicle initiation (30-0-0); FE10: fertilizer application at seedling stage (85-25-25) and at panicle initiation (70-0-0).

${ }^{\mathrm{f}} \mathrm{W} 1$ : field drained at 30 days after crop establishment; W2: field drained at 60 days after crop establishment; W3: field permanently flooded.

g Crop establishment: TR: transplanted; DS: direct (wet) seeded. 
Eleven injuries caused by rice pathogens, insects, and weeds were considered: bacterial leaf blight (BLB), sheath blight (SHB), rice tungro disease (RTD), brown spot (BS), dead hearts caused by stem borers $(\mathrm{DH})$, white heads caused by stem borers (WH), whorl maggot injury (WM), leaf blast (LB), neck blast (NB), and weed growth above (WA) or below (WB) the rice plants. These injuries were selected on the basis of their reported importance in tropical Asia $(24,26,28,52,53)$ and on their observed occurrence in farmers' fields (45). These injuries also differ in their corresponding damage mechanisms, which were reviewed by Pinnschmidt et al. (30). Using the classification terminology developed by Boote et al. (3), the damage mechanisms covered by these 11 injuries are: stand reduction (RTD and DH), photosynthetic rate reduction (BLB, BS, LB, $\mathrm{WA}$, and $\mathrm{WB}$ ), leaf senescence acceleration (BLB, SHB, BS, LB, WA, and WB), light stealing (BLB, SHB, BS, BS, LB, $\mathrm{WA}$, and $\mathrm{WB}$ ), and tissue consumption (BLB, SHB, BS, WH, WM, and NB). This array was considered representative of most of the damage mechanisms any rice pest may induce.

These yield-limiting and yield-reducing factors could not, of course, be addressed simultaneously in a single experiment. Table 1 shows the sequence of experiments conducted. This study is based on 11 successive experiments, totaling 445 individual plots. Three experiments were conducted in farmers' fields in the neighborhood of Los Baños, Philippines, while eight were conducted at IRRI's Central Research Farm.

A typical layout of experiments of the data base simultaneously involved two production factors (Table 1). These (e.g., fertilizer with two levels and water management with three levels) were arranged in a strip-plot design defining main units, in which subplots consisting of combinations of injury treatments were defined (39). Injury treatment subplots consisted of the eight possible combinations of three injuries (each of them at two levels) chosen among the 11 listed in Table 1. The two levels of each injury were (in most experiments): uninjured and injured due to artificial establishment of a pest(s) in the plot. The levels of injury depended on varying initial inoculum doses (or initial insect or weed population introduced) and/or environmental conditions, and in many cases the same injury was considered two or several times in different experiments. One key feature of this design was the existence of one control plot (no injuries) in each of the main units (i.e., combination of production factors) of any experiment. These uninjured plots measured the attainable yield corresponding to each main unit. This design thus measured the yield loss associated to each plot (i.e., the gap between individual plot yield and the attainable yield measured in the corresponding main unit) in any combination of injuries and production factors.

Another feature of the experiments is that use of pesticides was avoided as much as possible. Pesticide use may generate undesirable effects in rice as well as in other crops, such as enhancing crop growth (and thus invalidating yield comparisons; $51)$ or affecting populations of natural enemies of crop pests (24). The approach used in manipulating rice pests was based on artificial introduction of the harmful agents in the test plots, combined with large buffer areas between plots, rather than reliance on pesticides to control spontaneous development of diseases, weeds, and insect populations. One key issue was to minimize interplot interference (16) and thus achieve the desired injury treatments. This was especially important for control plots, where injuries must be negligible and attainable yield measured. Isolated microfields $(29,46,58)$ consisting of $12 \times 12$ rice hills at $20 \times 20$ $\mathrm{cm}$ spacing $(2.4 \times 2.4 \mathrm{~m}$ plots for directseeded rice) were used. The area of individual plots was $5.8 \mathrm{~m}^{2}$, and an experiment typically involved 48 such plots established in a $3,750 \mathrm{~m}^{2}$ rice field, so as to provide large buffer areas between plots. This plot size represents a compromise between (i) the amount of work required to inoculate or infest a number of individual plants, (ii) the representativeness of yield measurements and injuries at the plot level $(25,49,51)$, and (iii) the time required for successive injury assessments. The choice of plot size also took into account the size and strength of the inoculum source. When inoculated (infested), a microfield becomes a source of inoculum (pest) for the entire experiment. Should the plot size be large, this source may become very strong, as for instance in the case of tungro, where microfields were planted to a susceptible variety and were embedded in a comparatively large field planted to a resistant one. A point-source of tungro inoculum (see below) was established at the center of the plots to be inoculated, so that the vectors would first spread on susceptible plants of the same plot prior to encountering resistant ones on the large surface that separates two test plots.

Specific points on manipulation of individual injuries are listed below. These procedures are described in more detail in Savary et al. (39).

Bacterial leaf blight (BLB). Bacterial suspensions at a concentration of $10^{9}$ cells $\mathrm{ml}^{-1}$ were prepared from 72-h-old cultures of Xanthomonas campestris pv. oryzae grown on a modified Wakimoto's medium (20). Inoculations were done 7, 14, and 21 days after crop establishment (DACE), either by the leaf clipping method (21) on $50 \%$ of the leaves per plant or by spraying suspensions on the entire plot.

Sheath blight $(\mathrm{SHB})$. At maximum til- lering stage (about 45 DACE), all plants were inoculated by inserting into the center of each hill $5 \mathrm{~g}$ of a 10- to 14-day-old inoculum consisting of Rhizoctonia solani mycelium growing on a 1:4 rice grain-rice hull substrate $(28,37)$.

Rice tungro disease (RTD). Preparation of inoculum sources for RTD followed Ling (23): (i) individual 7-day-old seedlings of the susceptible rice variety $\mathrm{TN} 1$ were planted in pots; (ii) the pots were caged 30 days later; (iii) two to five viruliferous green leafhoppers (GLH) were introduced into each cage; (iv) 15 days later, when tungro symptoms were visible, the potted plants were transferred to the field, together with the vectors feeding on them. The pots (point sources) were placed at the center of each plot to be inoculated at 7 DACE. After about 10 days, the tungro source plants were removed, and the subsequent spread of RTD in the microfields depended on spontaneous GLH populations.

Brown spot $(B S)$. Spore suspensions $(3 \times$ $10^{4}$ spores $\mathrm{ml}^{-1}$ ) were prepared from 7day-old cultures of Cochliobolus miyabeanus grown on potato dextrose agar and were sprayed on the plots in the late afternoon at tillering and flowering stages. Water was sprayed on the plots three to four times daily to extend the leaf wetness duration during the following 5 days after inoculation.

Leaf $(L B)$ and neck blast $(N B)$. Spore suspensions were sprayed in the late afternoon on the plots at different doses $\left(10^{4}\right.$ to $3 \times 10^{4}$ spores $\mathrm{ml}^{-1}$ ) and at different times during and after heading to obtain various levels of LB and NB (31). Blast-inoculated plots were covered with plastic sheets during the night following the inoculation. In the particular case of blast, fungicides were used to prevent interplot interferences: tricyclazole or benomyl were sprayed on the noninoculated plots at the peak of blast epidemics in the inoculated ones.

Dead hearts $(D H)$. Artificial infestation of yellow stem borer Scirpophaga incertulas followed Pongprasert et al. (33). Moths were collected in the neighborhood of experiments and placed in cages containing potted rice plants, where they oviposited. After 5 days, when eggs were about to hatch, leaf portions with egg masses were clipped and inserted between the stem and the leaf sheath in plants to be infested. In each plot to be injured, one egg mass was inserted in each of the 20 plants per plot to be infested. Infestation was done at approximately 21 DACE.

White heads (WH). To generate white heads, plants were infested at a later stage (panicle initiation to early booting) with eggs of stem borers as described above for dead hearts. In this case, however, 30 hills per plot were infested.

Whorl maggot (WM). The method used follows Heinrichs et al. (15): 9 days after 
transplanting, adult flies of whorl maggot (Hydrellia philippina) were collected. Ten hills in each plot were enclosed in separate cylindrical Mylar film cages at the early tillering stage, and infestation was done by releasing 10 males and 10 females per cage. The cages were removed 7 days later.

Weed infestation above (WA) and below $(W B)$ the rice crop canopy. Seedlings of Echinochloa glabrescens and Leptochloa chinensis, which outgrow rice plants, were collected from nearby fields and planted in plots assigned to WA injury. Monochoria vaginalis and Sphenoclea zeylanica were used to represent weed infestation below the rice crop canopy (WB). Infestations for both WA and/or WB were done at 7 DACE. Weed-free plots were weeded at 20 to 25 DACE and again about 30 days later.

Observations were done at four development stages of the rice crop: tillering, booting, flowering, and ripening. Using a 0 to 100 development stage scale (P. S. Teng, unpublished), these stages correspond to 20, 40, 60, and 100 development stage units (dsu), respectively. These stages were selected so that injuries caused by the range of pests considered could be adequately represented at any crop development stage (39). Some injuries occurring in the plots were the result of manipulations (and reflected imposed treatments), while others were spontaneous. All observed injuries, including those resulting from spontaneous infections or infestations, were assessed using a standardized procedure (39), which is summarized here. Standardization of observations allowed data sets from successive experiments to be combined. Except for weed infestation, measurement of injuries was based on standard samples of five rice hills (or $10 \times$ $10 \mathrm{~cm}$ quadrats in direct-seeded plots). To prevent tramping inside the plots, these samples were chosen at random in an inner, circular strip in each experimental plot, $20 \mathrm{~cm}$ wide, immediately adjacent to a 20-cm-wide border (i.e., the square of plants inside each plot that were immediately adjacent to the border row of each plot in the case of transplanted plots). Injuries were quantified depending on the organ considered.

Injuries on the leaves: (i) injuries caused by whorl maggots (WM), leaf folders (LF), and other defoliators (OTH) were assessed as the mean proportions of injured leaves in the sample; (ii) injuries caused by foliar diseases such as bacterial blight (BLB), brown spot (BS), and leaf blast (LB) were measured by their severity assessed in the sample, considering all leaves of three tillers chosen at random in the five hills (or quadrats);

Injuries on tillers and panicles: (i) dead hearts (DH) and white heads (WH) were assessed as the proportion of injured tillers and panicles, respectively, in the five sampled hills (or quadrats); (ii) neck blast (NB) incidence was assessed as that of white heads, and panicle blast severity was assessed using the scale developed by Ahn and Mukelar (1); (iii) the sheath blight (SHB) injury was defined as: $I \times(S l+$ $S s) / 2$, where $I$ is the proportion of infected tillers in the five sampled hills (quadrats), $\mathrm{Sl}$ is the severity (proportion diseased area) on the leaves of three tillers in each of the five samples, and $S s$ is the severity on the sheaths of these tillers.

Injuries affecting an entire crop stand: (i) the incidence (percent diseased hills) of rice tungro disease (RTD) was derived from counts of infected and healthy hills in a plot. Symptom intensity per hill was then assessed from the five sample hills using a 0 to 8 rating system (39). The injury due to tungro was then defined as the product of incidence by the mean symptom intensity; (ii) weed infestations above (WA) and below (WB) the rice crop canopy were assessed simultaneously using a 0 to 4 rating scale (39) corresponding to proportions of ground coverage, either by weeds outgrowing the rice stand (WA) or not (WB).

Injury data were synthesized over four successive development stages $(20,40,60$, and $100 \mathrm{dsu}$ ) to account for the overall injury caused by individual pests during crop development. Overall injuries were expressed differently, depending on the nature of the harmful agents. These synthetic injury indices (Table 2) were defined as follows: (i) injuries affecting the entire development of the crop: BLB, BS, LB, WM, RTD, WA, and WB were represented by areas under injury progress curves (4) over development (measured as stage units, dsu, from 0 to 100); (ii) injuries affecting the rice crop at a specific development stage or showing a definite peak in their progress over time: SHB, NB, DH, and WH were represented by the maximum injury observed over the four assessments.

Assessment of individual plot yield was based on whole grain yield estimates (converted to a $14 \%$ moisture content) excluding the borders, i.e., an area of 4.84 $\mathrm{m}^{-2}$ (i.e., $11 \times 11$ hills or 121 quadrats, 400 $\mathrm{cm}^{2}$ each).

Data synthesis using nonparametric techniques. A multivariate approach similar to that used for analyzing survey data $(38,43,44)$ was used to provide an overview of the structure of the data base. This approach involves three successive steps: (i) categorization of data, (ii) building of contingency tables and chi-square tests, and (iii) correspondence analysis.

The distribution frequencies of injury levels followed a common general pattern: a large number of plots with null or low injury levels, a fraction of the population of plots with intermediate injury levels (resulting in most cases from inoculation or infestation), and a fraction of plots with high injury levels (resulting from successful establishment of the pest population). The levels of a given injury, $\mathrm{X}$, were thus initially categorized as $\mathrm{X} 0$ (absence), $\mathrm{X} 1$

Table 2. List of variables considered in the analysis of the experimental yield-loss data base for tropical lowland rice

\begin{tabular}{|c|c|c|c|}
\hline Variable type & Symbol & Variable description & Unit \\
\hline \multicolumn{4}{|l|}{ Injuries } \\
\hline & SHB & Maximum sheath blight severity & (\%) \\
\hline & BLB & Area under the progress curve of bacterial leaf blight severity (4 assessments) & $\left(\% \mathrm{dsu}^{\mathrm{a}}\right)$ \\
\hline & RTD & $\begin{array}{l}\text { Maximum rice tungro disease intensity (proportion of infected rice plants } \times \text { symptom intensity on a } 0 \text { to } \\
8 \text { scale) }\end{array}$ & (None) \\
\hline & BS & Area under the progress curve of brown spot severity ( 4 assessments) & $(\% \mathrm{dsu})$ \\
\hline & LB & Area under the progress curve of leaf blast severity ( 4 assessments) & $(\% \mathrm{dsu})$ \\
\hline & NB & Maximum percentage of panicles with neck or panicle blast symptoms & (\%) \\
\hline & WM & Area under the progress curve of mean percentage of leaves with whorl maggot injury ( 4 assessments) & $(\% \mathrm{dsu})$ \\
\hline & DH & Maximum percentage of tillers with dead heart (stem borers) injury & $(\%)$ \\
\hline & WH & Maximum percentage of panicles with white head (stem borers) injury & (\%) \\
\hline & WA & $\begin{array}{l}\text { Area under progress curve of percent ground coverage of weeds growing above the crop canopy } \\
\text { (4 assessments) }\end{array}$ & $(\% \mathrm{dsu})$ \\
\hline & WB & $\begin{array}{l}\text { Area under progress curve of percent ground coverage of weeds growing below the crop canopy } \\
\text { (4 assessments) }\end{array}$ & $(\% \mathrm{dsu})$ \\
\hline \multicolumn{4}{|c|}{ (7) } \\
\hline & $\mathrm{Y}$ & Actual plot yield (grain yield, $14 \%$ moisture) & $\left(\mathrm{t} \mathrm{ha}^{-1}\right)$ \\
\hline & Ya & Attainable yield & $\left(\mathrm{t} \mathrm{ha}^{-1}\right)$ \\
\hline & YL & Yield loss: Ya - Y & $\left(\mathrm{t} \mathrm{ha}^{-1}\right)$ \\
\hline
\end{tabular}

a dsu: development stage units on a 0 to 100 scale. 
(low), X2 (medium), and X3 (high). Attention was paid to the definition of the numerical boundaries of each class to ensure that each category would have a sufficient class filling, in order to enable statistically valid chi-square tests (8). The initial categorization was thus altered to meet this prerequisite. For many injuries (RTD, BS, LB, NB, WA), a categorization in four classes would have led to too few plots falling into the medium (X2) category. Three categories were thus considered in these cases: X0 (absence), X1 (low), and $\mathrm{X} 2$ (high). In one case (WM), only a few plots were free from spontaneous injury, and the absence and low classes were merged and three categories were defined: X1 (low), X2 (medium), and X3 (high). Table 3 summarizes the categories used in the next steps of the analysis.

Variation in yield loss, YL, was represented by five successive categories (Table 3) with numerical boundaries defined to achieve similar class sizes. A larger number of classes allowed us to describe more accurately, and test relationships between, yield loss and individual injuries, as well as to better interpret multiple relationships in a correspondence analysis.

Numerical boundaries were defined to categorize both actual (Y) and attainable (Ya) yields (Table 3) so that: (i) five classes would be defined for $\mathrm{Y}$, from very low (Y1) to very high (Y5), (ii) similar class sizes would be achieved in each category, and (iii) no attainable yield would fall below the numerical boundary defining lowest yields, i.e., no attainable yield would be categorized as very low. Thus, four categories were defined for Ya.

A series of [YL $\times$ injury] contingency tables was built to analyze relationships between injury levels and yield losses, and the corresponding chi-square tests were performed to test the null hypothesis of independence of distributions of injuries and yield loss levels. Correspondence analysis $(2,9,13)$ was then used to synthesize the structure of the data set in a pictorial way and to hierarchize injuries with respect to their yield-reducing effect. This technique is convenient for synthesizing information contained in one or (as here) several contingency tables and where many relationships, while strong and statistically significant (as can be tested by a chisquare), are not linear (43). As in principal component analysis, correspondence analysis generates a series of axes. These axes reflect the bivariate frequency distributions in each of the contingency tables used. In addition to their coordinates along axes, classes are represented by their relative weights, contribution to axis, and reciprocal contribution to axis $(2,9,13,43)$. The relative weight (or mass) of each class represents the frequency of individuals in the corresponding row (or column). The contribution to an axis is the proportion of inertia of that axis derived from a specified class. The reciprocal contribution represents the proportion of inertia of the class (row or column) that is accounted for by the specified axis. It is also the correlation between the axis and the class. Finally, the sign of the coordinate indicates the direction along which each class deviates from the origin. Interpretation of graphs generated by correspondence analysis can be outlined as follows $(9,13,43)$. Proximity of points representing classes on a factorial plane indicates associations, i.e., correspondences that can be checked using the shape of contingency tables and the associated chi-square tests. When a series of classes representing successive levels of a categorized quantitative variable that reflects a logical increase (e.g., yield loss, YL0 to YL4) is considered, a path linking the successive classes can be drawn, and the movement along this path may be examined in relation with positions of other classes. The successive levels of a path for a given variable can thus be associated to a series of categorized levels (classes) of other variables. For instance, correspondences linking successive yield-loss categories with various injury levels can be checked and outlined as domains on the graph using the underlying contingency tables and chi-square tests.

Yield loss estimation and scenario analyses using multivariate parametric techniques. Numerous multivariate, parametric methods are available to analyze such a data set (22). The approach has to estimate yield losses due to specific injuries and to combinations of injuries at specified attainable yields. The latter objective is of prime importance, because interactions among injuries in their yieldreducing effects, which may vary in intensity depending on production situations, are to be expected. Results from surveys in various Asian sites $(12,38,44)$, as well as across tropical Asia (45), indicate that injury profiles depend on production situations. The approach to analyze this data base should therefore also consider scenarios where a production situation (represented here by a given attainable yield) is chosen, a given injury profile corresponding to this production situation is selected, and the resulting yield losses are estimated.

The approach chosen (11) involves four steps: a principal component analysis, a multiple regression analysis, evaluation of the resulting empirical model, and analysis

Table 3. Categorization of variables involved in the experimental rice yield-loss data base for tropical lowland rice

\begin{tabular}{|c|c|c|c|}
\hline Variable type & Symbol $^{\mathbf{a}}$ & Categories & Category definition $^{b}$ \\
\hline \multicolumn{4}{|l|}{ Injuries } \\
\hline & SHB & SHB0, SHB1, SHB2, SHB3 & $\begin{array}{l}\text { SHB0: SHB }=0 \% \text {; SHB1: } 0<\text { SHB } \leq 6 \% \text {; SHB2: } 6<\text { SHB } \leq 18 \% \text {; SHB3: } 18<\text { SHB } \leq \\
50 \%\end{array}$ \\
\hline & BLB & BLB0, BLB1, BLB2, BLB3 & $\begin{array}{l}\text { BLB0: } \mathrm{BLB}=0 \% \text { dsu; BLB1: } 0<\mathrm{BLB} \leq 80 \% \text { dsu; BLB2: } 80<\mathrm{BLB} \leq 370 \% \text { dsu; BLB3: } \\
370<\mathrm{BLB} \leq 2,500 \% \text { dsu }\end{array}$ \\
\hline & RTD & RTD0, RTD1, RTD2 & RTD0: RTD = 0; RTD1: $0<$ RTD $\leq 20 ;$ RTD2: $20<$ RTD $\leq 400$ \\
\hline & BS & BS0, BS1, BS2 & BS0: $\mathrm{BS}=0 \%$ dsu; $\mathrm{BS} 1: 0<\mathrm{BS} \leq 50 \%$ dsu; $\mathrm{BS} 2: 50<\mathrm{BS} \leq 200 \%$ dsu \\
\hline & LB & LB0, LB1, LB2 & LB0: LB $=0 \%$ dsu; LB1: $0<\mathrm{LB} \leq 10 \%$ dsu; LB2: $10<\mathrm{LB} \leq 300 \%$ dsu \\
\hline & NB & NB0, NB1, NB2 & NB0: NB $=0 \% ; \mathrm{NB} 1: 0<\mathrm{NB} \leq 30 \% ; \mathrm{NB} 2: 30<\mathrm{NB} \leq 70 \%$ \\
\hline & WM & WM1, WM2, WM3 & $\begin{array}{l}\text { WM1: } 0 \leq \mathrm{WM} \leq 500 \% \text { dsu; WM2: } 500<\mathrm{WM} \leq 1,000 \% \text { dsu; WM3:1,000 }<\mathrm{WM} \leq \\
2,500 \% \text { dsu }\end{array}$ \\
\hline & DH & DH0, DH1, DH2, DH3 & DH0: $\mathrm{DH}=0 \%$; DH1: $0<\mathrm{DH} \leq 2.5 \%$; DH2: $2.5<\mathrm{DH} \leq 10 \%$; DH3: $10<\mathrm{DH} \leq 50 \%$ \\
\hline & WH & WH0, WH1, WH2, WH3 & WH0: $\mathrm{WH}=0 \%$; WH1: $0<\mathrm{WH} \leq 4 \%$; WH2: $4<\mathrm{WH} \leq 10 \%$; WH3: $10<\mathrm{WH} \leq 40 \%$ \\
\hline & WA & WA0, WA1, WA2 & WA0: WA $=0 \%$ dsu; WA1: $0<$ WA $\leq 1,100 \%$ dsu; WA2: $1,100<$ WA $\leq 4,000 \%$ dsu \\
\hline & WB & WB0, WB1, WB2, WB3 & $\begin{array}{l}\text { WB0: WB }=0 \% \text { dsu; WB1: } 0<\mathrm{WB} \leq 1,450 \% \text { dsu; WB2: } 1,450<\mathrm{WB} \leq 2,500 \% \text { dsu; } \\
\text { WB3: } 2,500<\mathrm{WB} \leq 6,000 \% \text { dsu }\end{array}$ \\
\hline \multicolumn{4}{|r|}{ 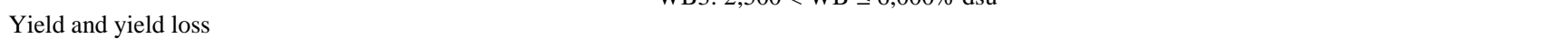 } \\
\hline & YL & YL0, YL1, YL2, YL3, YL4 & $\begin{array}{l}\text { YL0: YL }<0.25 \mathrm{tha}^{-1} ; \mathrm{YL} 1: 0.25<\mathrm{YL} \leq 0.75 \mathrm{tha}^{-1} ; \mathrm{YL} 2: 0.75<\mathrm{YL} \leq 1.25 \mathrm{tha}^{-1} ; \mathrm{YL} 3: \\
1.25<\mathrm{YL} \leq 1.90 \mathrm{t} \mathrm{ha}^{-1} ; \mathrm{YL} 4: 1.90<\mathrm{YL} \leq 4.50 \mathrm{t} \mathrm{ha}^{-1}\end{array}$ \\
\hline & Y & $\mathrm{Y} 1, \mathrm{Y} 2, \mathrm{Y} 3, \mathrm{Y} 4, \mathrm{Y} 5$ & $\begin{array}{l}\mathrm{Y} 1: \mathrm{Y}<2.40 \mathrm{tha}^{-1} ; \mathrm{Y} 2: 2.40<\mathrm{Y} \leq 3.80 \mathrm{tha}^{-1} ; \mathrm{Y} 3: 3.80<\mathrm{Y} \leq 5.20 \mathrm{t} \mathrm{ha}^{-1} ; \mathrm{Y} 4: 5.20<\mathrm{Y} \leq \\
6.90 \mathrm{t} \mathrm{ha}^{-1} ; \mathrm{Y} 5: 6.90<\mathrm{Y} \leq 11.47 \mathrm{t} \mathrm{ha}^{-1}\end{array}$ \\
\hline & Ya & Ya1, Ya2, Ya3, Ya4 & $\begin{array}{l}\text { Ya1: } 2.40<\mathrm{Ya} \leq 3.80 \mathrm{t} \mathrm{ha}^{-1} ; \mathrm{Ya} 2: 3.80<\mathrm{Ya} \leq 5.20 \mathrm{t} \mathrm{ha}^{-1} ; \mathrm{Ya} 3: 5.20<\mathrm{Ya} \leq 6.90 \mathrm{t} \mathrm{ha}^{-1} \\
\text { Ya4: } 6.90<\mathrm{Ya} \leq 11.47 \mathrm{t} \mathrm{ha}^{-1}\end{array}$ \\
\hline
\end{tabular}

\footnotetext{
a Symbols for variables and their units are listed in Table 2.

${ }^{\mathrm{b}}$ Categories for variables are defined by their numerical boundaries.
} 
of scenarios using this model. First, a normalized principal component analysis was conducted on the injury variables (Table 2 ), which led to the generation of a series of independent injury factors, $F_{i}$ (i.e., independent linear combinations of injuries). Second, these factors, together with attainable yield (Ya), were used in an upward, stepwise multiple regression analysis of variation in actual yield (Y), with the aim of generating an equation that describes the actual yield response surface. The tested equation (equation 1) had the following shape: $Y=a Y a+\Sigma b_{i} F_{i}+\Sigma c_{j} Y a \times F_{j}+$ $\Sigma \Sigma d_{k, l} F_{k} \times F_{l}$, where the $c_{j} Y a \times F_{j}$ and the $d_{k, l} F_{k} \times F_{l}$ terms account for interactions between attainable yield and injury factors, and among injury factors, respectively. Third, the resulting equation was assessed by aptness of residuals (11), coefficient of determination, and $F$ test. Fourth, the regression model was used to assess yield losses in various scenarios. Estimation of yield losses for all scenario analyses entailed back-computations using the yield response surface (equation 1). Each factor value was computed using its loadings and the considered (normalized) injury level(s); a preset attainable yield value was then entered in the equation; an estimate for actual yield was thus derived; and the difference $Y a-Y$, i.e., yield loss, was calculated.

Three types of scenarios were considered. The first type dealt with the potential losses a given injury may cause at varying injury levels and within a range of attainable yields. Yield losses caused by individual injuries were computed within the range of injury levels achieved through manipulation of pests in the series of field experiments. The second type of scenario was derived from survey data in tropical Asia and was aimed at estimating overall yield losses and at ranking the relative importance of rice pests region-wide. One elementary result of the survey (45) consists of measurements of individual injury levels in a population of 456 farmers' fields. The distribution frequencies of injury levels were not normal, and two distribution parameters were used to represent each injury in this second type of scenario: its mean and its median. Another survey result is the mean actual yield in farmers' fields: $\mathrm{Ym}=4.12 \mathrm{t} \mathrm{ha}^{-1}$, with a standard deviation of $1.41 \mathrm{t} \mathrm{ha}^{-1}$. Estimates of attainable yield were not, of course, available from farmers' fields. A mean attainable yield of about $\mathrm{Ym}+1$ standard deviation was considered a reasonable level, so that a fixed attainable yield of 5.5 $\mathrm{t} \mathrm{ha}^{-1}$ was used for the computation of yield losses. The third type of scenario dealt with losses caused by specified injury profiles. The survey of rice pests in tropical Asia also led to the characterization of a series of injury profiles (IN), which were shown to be strongly linked with given production situations represented by specific patterns of cropping practices (PR). While these clusters of PR and IN are associated (i.e., a given IN predominates in a significant way when a specific PR is encountered), it was also shown that these clusters of PR and IN were not site-specific. When considered simultaneously as new, synthetic variables, the IN and PR clusters also aptly described the variation in actual yield across the region. A set of scenarios was therefore considered where (i) a given injury profile IN was considered, and (ii) an attainable yield level was chosen corresponding to the PR most frequently associated with the IN. As in the previous type of scenario, no estimates for attainable yields were available, and Ya was thus arbitrarily set to one standard deviation above the mean yield value for each PR-cluster. Only the PR $\times$ IN combinations represented by a sample of at least $n=30$ fields were considered (45): PR $1 \times$ $\mathrm{IN} 1, \mathrm{PR} 3 \times \mathrm{IN} 3, \mathrm{PR} 5 \times \mathrm{IN} 2$, and PR6 $\times$ IN2.

\section{RESULTS}

Chi-square tests between injury levels and yield loss classes. Table 4 summarizes the successive tests made to assess the linkages between injury levels and yieldloss classes. In all cases, the null hypothesis of independence of yield loss and injury levels was rejected. Four types of significant linkages between injuries and yield losses were distinguished on the basis of bivariate frequency distributions (34) displayed in the contingency tables (not shown): high injury levels associated (i) with low yield losses (BLB and WM), (ii) with medium to high yield losses (SHB, $\mathrm{BS}, \mathrm{LB}, \mathrm{NB}$, and $\mathrm{DH}$ ), (iii) with a range of yield losses, up to high or very high (WH, WA, WB), and (iv) with injuries at any level (low to high) that appear to be associated with very high yield losses only (RTD).

Correspondence analysis. Among the several axes correspondence analysis generated, the two first ones accounted for an accumulated inertia (variance) of $82.3 \%$ (Table 5). These two axes therefore provided a good description of the categorized levels of injuries, as well as of the levels of yield losses, and are discussed here.

Examination of correspondence analysis results starts with the interpretation of axes, which is based on the contributions to axes $(9,13)$. Among the injuries that contribute much to the definition of the first (horizontal) axis (contributions to axis 1, Table 5), the successive levels of SHB have an important role. The levels of SHB exhibit a gradient of coordinates $(-0.099$, $-0.072,0.210$, and 0.364 , for SHB0, SHB1, SHB2, and SHB3, respectively) along this axis, from absent (SHB0, with a negative coordinate and a large absolute value) to high (SHB3, with a positive coordinate and a large absolute value): movement along axis 1 thus coincides with increasing levels of SHB. Note that the extreme levels of the series (SHB0 and SHB3) correspond to the largest contribution to axis 1 (1.55 and 4.68 , respectively), reflecting their increasing distance from the origin of axes, thus their inertia. Similar gradients are observed in the case of BS, WA, WB, and RTD. In the latter case, absence (RTD0, coordinate -0.079) is opposed to presence of tungro (RTD1 and RTD2, coordinates 0.531 and 0.641 , respectively). Movement in the positive direction along axis 1 , however, corresponds to decreasing levels of BLB and WM. In the case of BLB, absence of BLB (with a large BLB0 contribution to axis in the positive direction) is

Table 4. Chi-square tests on the effects of injuries ( $\mathrm{Y}$ variables) on levels of yield losses (X variable) in the experimental data base for tropical lowland rice

\begin{tabular}{|c|c|c|c|c|}
\hline Variable $^{a}$ & $\chi_{(\mathbf{X}, \mathbf{Y})}^{\mathbf{b}}$ & df & $\boldsymbol{P}$ & Comments derived from examination of contingency tables \\
\hline SHB & 40.2 & 12 & $<0.0001$ & High SHB associated with medium (YL2) to high (YL3) losses \\
\hline BLB & 57.1 & 12 & $<0.0001$ & High BLB associated low (YL1) losses \\
\hline RTD & 25.2 & 8 & 0.001 & RTD, low or high, associated with high (YL3) or very high (YL4) losses \\
\hline BS & 26.2 & 8 & 0.001 & High BS associated with high (YL3) losses \\
\hline LB & 17.7 & 4 & 0.005 & High LB associated with high (YL3) losses \\
\hline NB & 16.0 & 4 & 0.005 & High NB associated with high (YL3) losses \\
\hline WM & 35.0 & 8 & $<0.0001$ & High WM associated with low (YL1) losses \\
\hline DH & 20.8 & 12 & 0.05 & High DH associated with medium (YL2) or high (YL3) losses \\
\hline WH & 26.1 & 12 & 0.01 & High WH associated with high (YL3) or very high (YL4) losses \\
\hline WA & 19.7 & 8 & 0.01 & High WA associated with high (YL4) losses \\
\hline WB & 37.8 & 12 & 0.0002 & High WB associated with losses ranging from low (YL1) to very high (YL4) \\
\hline
\end{tabular}

a See Table 1 for variable list.

${ }^{\mathrm{b}}$ Contingency tables for manipulated injuries (X) and measured yield losses (Y) were built using categories defined in Table 3. 
opposed to successive levels of BLB (BLB1-3, in the negative direction). With respect to injuries, the first axis may thus be interpreted as representing increasing levels of SHB, RTD, BS, WA, and WB, but decreasing levels of BLB and WM. Similar gradients can be detected along the second vertical axis. This axis is associated with increasing levels of SHB, BS, LB, $\mathrm{NB}, \mathrm{DH}$, and WH. Prominent contributions of the highest levels of BS and NB (BS2 and NB2) are indicated by very large contributions to axis 2. Decreasing levels of WB are also indicated along this axis, with comparatively small contributions, however. The second axis may thus be interpreted as representing increasing levels of several injuries (SHB, BS, LB, NB, DH, and $\mathrm{WH}$ ), especially $\mathrm{BS}$ and $\mathrm{NB}$, and slightly decreasing levels of WB. It is worth noting that most of the reciprocal contributions of injury classes accumulated over axes 1 and 2 exceed $70 \%$. This indicates that the combination of these two axes provides good descriptions of levels of the various injuries.

Interpretation of axes has also to be made according to the other set of classes, yield-loss levels. A gradient of coordinates of the yield-loss classes (YL0 to YL4) is observed along axis 1, YL0 and YL1 having large, negative coordinates, whereas coordinates for YL2, YL3, and YL4 are increasingly positive. The contributions YL0, YL1, and YL4 to axis 1 are particularly large. The first axis may thus be in- terpreted as representing increasing levels of yield losses. The second axis strongly opposes high losses, YL3 (in the positive direction), on the one hand, and very high losses, YL4, or negligible losses, YL0 (in the negative direction), on the other. These three yield-loss categories have large contributions to axis 2. The second axis may thus be interpreted as a contrast between extreme loss levels, either very high or negligible, and high yield-loss levels. The accumulated inertia of yield-loss classes accounted for by both axes is large, ranging from about $60 \%$ (YL0, YL1) to over 90\% (YL3, YL4), except for medium yield losses, YL2 $(22.11 \%)$. YL2 having the smallest coordinates (in absolute terms) on both axes, this yield-loss class is thus close

Table 5. Correspondence analysis of injury levels and yield-loss levels achieved in the experimental data base: relative weights and contribution to axes

\begin{tabular}{|c|c|c|c|c|c|c|c|c|}
\hline & \multirow[b]{3}{*}{ Classes } & \multirow{3}{*}{$\begin{array}{l}\text { Relative } \\
\text { weight }^{\text {a }}\end{array}$} & \multicolumn{3}{|c|}{ Axis 1} & \multicolumn{3}{|c|}{ Axis 2} \\
\hline & & & \multirow[b]{2}{*}{ Coordinate } & \multicolumn{2}{|c|}{ Contribution } & \multirow[b]{2}{*}{ Coordinate } & \multicolumn{2}{|c|}{ Contribution } \\
\hline & & & & To axis ${ }^{b}$ & Reciprocal $^{\mathrm{c}}$ & & To axis $^{\mathrm{a}}$ & Reciprocal $^{\mathrm{c}}$ \\
\hline \multicolumn{9}{|l|}{ Rows } \\
\hline & SHB0 & 0.046 & -0.099 & 1.55 & 21.01 & -0.184 & 5.88 & 72.24 \\
\hline & SHB1 & 0.022 & -0.072 & 0.40 & 37.40 & 0.015 & 0.02 & 1.72 \\
\hline & SHB2 & 0.013 & 0.210 & 1.99 & 19.87 & 0.368 & 6.73 & 61.02 \\
\hline & SHB3 & 0.010 & 0.364 & 4.68 & 49.94 & 0.304 & 3.59 & 34.76 \\
\hline & BLB0 & 0.050 & 0.251 & 10.85 & 88.10 & 0.000 & 0.00 & 0.00 \\
\hline & BLB1 & 0.020 & -0.295 & 6.04 & 72.35 & -0.067 & 0.34 & 3.71 \\
\hline & BLB2 & 0.008 & -0.251 & 1.83 & 60.18 & 0.180 & 1.04 & 30.89 \\
\hline & BLB3 & 0.013 & -0.314 & 4.51 & 28.28 & -0.025 & 0.03 & 0.78 \\
\hline & RTD0 & 0.080 & -0.079 & 1.72 & 92.25 & 0.010 & 0.03 & 1.62 \\
\hline & RTD1 & 0.006 & 0.531 & 6.27 & 71.21 & -0.269 & 1.77 & 18.26 \\
\hline & RTD2 & 0.005 & 0.641 & 7.13 & 94.75 & 0.148 & 0.42 & 5.05 \\
\hline & BSO & 0.082 & -0.021 & 0.13 & 9.07 & -0.066 & 1.39 & 89.10 \\
\hline & $\mathrm{BS} 1$ & 0.004 & 0.020 & 0.01 & 0.20 & 0.390 & 2.32 & 79.75 \\
\hline & BS2 & 0.005 & 0.412 & 2.83 & 21.11 & 0.786 & 11.32 & 76.74 \\
\hline & LB0 & 0.084 & 0.013 & 0.05 & 5.01 & -0.055 & 0.95 & 94.68 \\
\hline & LB1 & 0.004 & -0.239 & 0.87 & 15.08 & 0.525 & 4.63 & 72.70 \\
\hline & LB3 & 0.002 & 0.175 & 0.23 & 3.81 & 0.830 & 5.79 & 86.06 \\
\hline & NB0 & 0.084 & 0.010 & 0.03 & 3.34 & -0.056 & 1.02 & 96.40 \\
\hline & NB1 & 0.003 & -0.336 & 1.02 & 85.40 & -0.055 & 0.03 & 2.30 \\
\hline & NB2 & 0.004 & 0.100 & 0.13 & 0.67 & 1.166 & 19.73 & 91.25 \\
\hline & WM0 & 0.031 & 0.233 & 5.78 & 76.63 & -0.076 & 0.68 & 8.15 \\
\hline & WM1 & 0.039 & -0.219 & 6.50 & 55.54 & 0.186 & 5.17 & 40.13 \\
\hline & WM2 & 0.019 & -0.093 & 0.58 & 25.75 & -0.150 & 1.67 & 66.65 \\
\hline & DH0 & 0.017 & 0.052 & 0.16 & 3.29 & -0.237 & 3.70 & 68.31 \\
\hline & DH1 & 0.028 & -0.158 & 2.43 & 65.97 & -0.072 & 0.57 & 13.94 \\
\hline & DH2 & 0.027 & 0.045 & 0.19 & 31.02 & 0.055 & 0.31 & 47.39 \\
\hline & DH3 & 0.019 & 0.140 & 1.29 & 24.64 & 0.237 & 4.07 & 70.46 \\
\hline & WHO & 0.027 & 0.137 & 1.79 & 32.20 & -0.192 & 3.86 & 63.06 \\
\hline & WH1 & 0.026 & -0.128 & 1.46 & 98.18 & -0.002 & 0.00 & 0.02 \\
\hline & WH2 & 0.019 & -0.227 & 3.41 & 46.54 & 0.232 & 3.91 & 48.45 \\
\hline & WH3 & 0.019 & 0.216 & 3.11 & 81.94 & 0.039 & 0.11 & 2.68 \\
\hline & WA0 & 0.069 & -0.032 & 0.24 & 10.22 & 0.057 & 0.87 & 33.85 \\
\hline & WA1 & 0.015 & -0.050 & 0.13 & 2.50 & -0.192 & 2.05 & 36.48 \\
\hline & WA2 & 0.008 & 0.412 & 4.58 & 72.97 & -0.166 & 0.82 & 11.81 \\
\hline & WB0 & 0.034 & -0.081 & 0.77 & 24.42 & 0.099 & 1.26 & 36.42 \\
\hline & WB1 & 0.021 & -0.169 & 2.11 & 51.95 & -0.127 & 1.32 & 29.43 \\
\hline & WB2 & 0.020 & -0.058 & 0.23 & 16.41 & 0.100 & 0.77 & 49.35 \\
\hline & WB3 & 0.016 & 0.481 & 13.00 & 73.50 & -0.172 & 1.84 & 9.44 \\
\hline \multicolumn{9}{|l|}{ Columns } \\
\hline & YL0 & 0.209 & -0.146 & 15.45 & 35.83 & -0.123 & 11.99 & 26.66 \\
\hline & YL1 & 0.196 & -0.185 & 23.18 & 57.48 & -0.059 & 2.61 & 5.86 \\
\hline & YL2 & 0.203 & -0.016 & 0.18 & 1.49 & 0.059 & 2.72 & 20.62 \\
\hline & YL3 & 0.209 & 0.071 & 3.66 & 6.03 & 0.276 & 60.67 & 90.70 \\
\hline & YL4 & 0.183 & 0.301 & 57.53 & 73.79 & -0.178 & 22.01 & 25.62 \\
\hline \multicolumn{9}{|c|}{ Inertia accounted for by axes } \\
\hline
\end{tabular}

${ }^{a}$ Relative weight (or mass) of each class represents the frequency of individuals in the corresponding row (or column).

${ }^{\mathrm{b}}$ Contributions to axes are the proportions of inertia of axes derived from classes.

${ }^{\mathrm{c}}$ Reciprocal contributions (or correlations between axes and classes) represent proportions of inertia of classes (row or column) accounted for by axes. 
to the origin of axes and therefore cannot be expected to have a large inertia. The large fraction of accumulated inertia accounted for by axes 1 and 2 indicates that the variation in yield-loss levels is well described by this combination of axes.

Figure 1 shows the projection of the various classes (injury levels and classes of yield losses) on the plane defined by axes 1 and 2. In Figure 1A, all classes are shown, so as to visualize their proximity (with a chi-square distance). In Figure 1B, the successive yield-loss classes have been plotted again using the same scale and linked in a path of increasing yield-loss levels. Figure 1C provides an interpretation of relationships among injury levels and this path of increasing yield losses. In Figure $1 \mathrm{~A}$, the proximity between two classes indicates their linkage, which increases with increasing distance of classes from the origin of axes (9). While a number of injury levels seem associated with YL0, YL1, and YL2, fewer seem linked with the two other levels of yield losses, especially YL3. Figure 1B exhibits a regular path of increasing yield losses, as suggested by examination of coordinates (Table 5).

A pictorial interpretation of the analysis can be made using Figure 1C. Low yieldloss levels (YL1) are associated with low levels of some injuries (WB1, DH1, WH1, PB1) but variable levels of BLB (BLB1,
BLB2, or BLB3). Medium yield losses (YL2) are associated with low levels of some injuries (SHB1, WM1), medium levels of others (WB2, DH2, and WH2), and variable levels of BLB (BLB2 and BLB3). High yield losses (YL3) correspond to medium or high levels of SHB (SHB2 or SHB3), high levels of DH and NB (DH3, NB2), and any level-i.e., occurrence - of LB and BS (LB1 or LB2, and BS1 or BS2). Very high yield losses are associated with high levels of some injuries (WA2, WB3, WH3) and any level (occurrence) of RTD (RTD1 or RTD2).

Figure 1C therefore provides a good summary of the successive tests (Table 4) and of the interpretation of axes (Table 5). It offers a qualitative overview of the experimental yield-loss data base, with four broad groups of injuries and four corresponding levels of yield losses.

Principal component and multiple regression analyses. Principal component analysis on injury variables yielded a series of 11 factors (totaling 100\% variance explained), $F_{i}$, that can be seen as independent linear combinations of the (normalized) injury variables (11), and these were used in the next steps of the analysis.

The results of the step-wise multiple regression analysis of the variation in actual yield, $Y$, using the $F_{i} s$, the variation in attainable yield (Ya), and their interactions are summarized in Table 6. Overall, a very good description of the variation of $\mathrm{Y}$ was achieved, with an $R^{2}$ value of $97.8 \%$ and a Fisher ratio of 2269. Examination of residuals (Fig. 2) does not suggest that hypotheses pertaining to the errors associated with this regression are violated (11).

The resulting regression includes several interactions that significantly contribute to describe variation in actual yield. Interaction terms of the form: Ya $\times F_{i}$ reflect yield-reducing effects that depend on the level of attainable yield. Interaction terms of the form: $F_{j} \times F_{k}$ refer to competition, or synergies, of injuries in their yield-reducing effect. While the construction of the regression makes its interpretation in detail difficult, the significant contribution of these interactions to the tested model represents a key result of the analysis: (i) injuries (or some of them at least) interact with attainable yield in the damage they cause, and (ii) some injuries interact in their yield-reducing effects. Interpretation of the regression as a whole can be addressed through its behavior and considered by means of scenario analysis. The outcomes of some of these scenarios are reported below.

Yield losses caused by individual injuries. In the first set of scenarios, a range of attainable yields was considered, and a few injuries were allowed to vary (one injury at

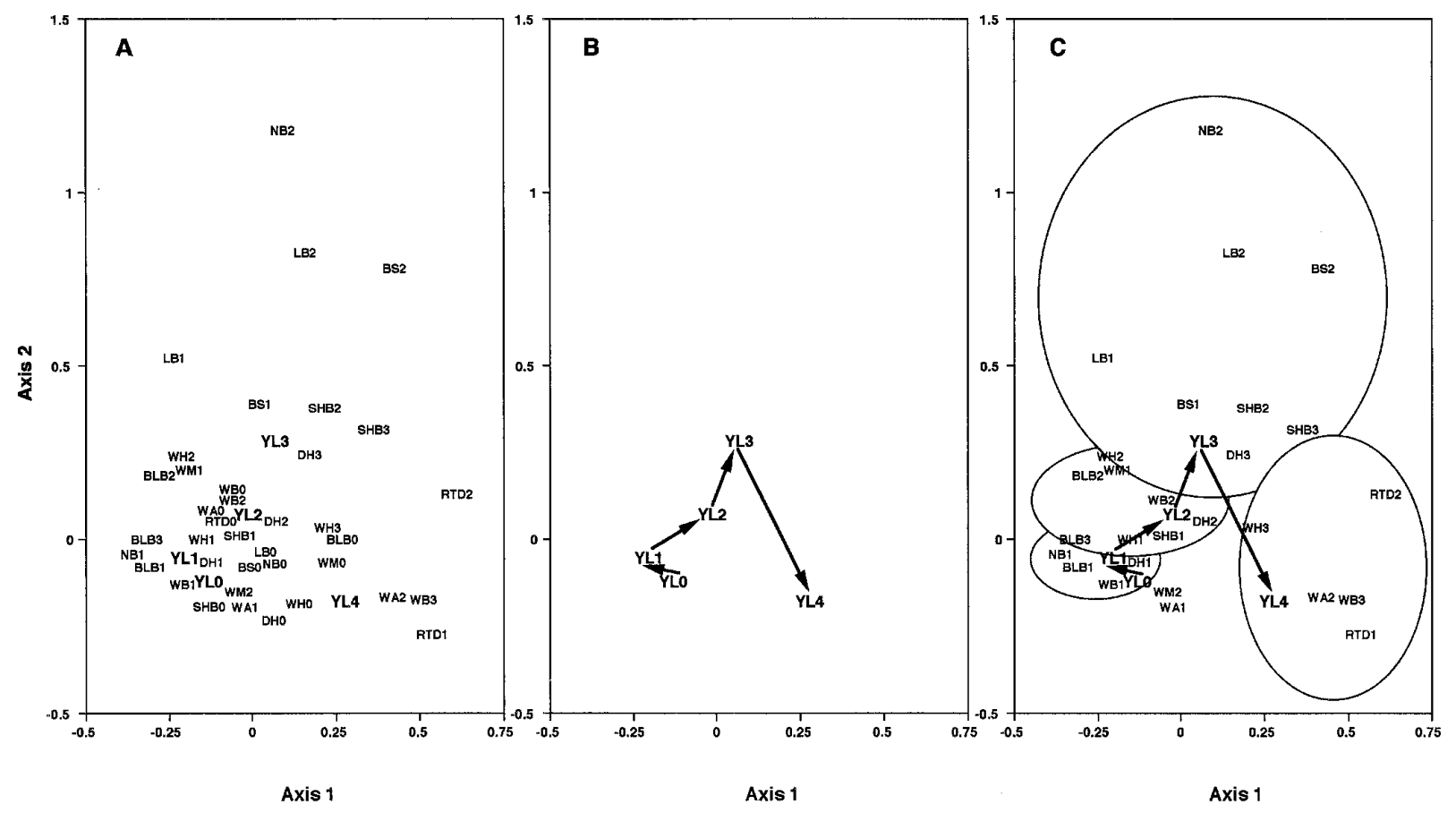

Fig. 1. Correspondence analysis of the relationships among categorized levels of injuries and yield losses for lowland rice. Categories are defined in Table 3. Variables (injury levels and levels of yield losses) are plotted on the two first axes, accounting for $43.1+39.2=82.3 \%$ of total inertia (Table 5). (A) Biplot representation of all variables using their coordinates on the two first axes (Table 5). The units shown on the axes are chi-square distances. Proximity of categories on the factorial plane indicates correspondences derived from, and tested on, contingency tables. (B) Location of the five levels of yield losses, from negligible (YL0) to very high (YL4) on the same factorial plane. A path of increasing levels of losses is indicated. (C) Interpretation of the correspondence analysis, showing four broad domains of injuries and their relationships with the successive levels of losses. The successive levels of the yield-loss path are associated to a series of categorized levels of injuries based on contingency tables and chi-square tests (Table 4). These multiple associations are outlined as domains. 
a time). The results for three injuries are shown in Figure 3, where SHB, RTD, and WB were allowed to vary independently. Each curve indicates the response in relative yield loss to increasing injury levels at specified attainable yields: 2, 4, 6, 8, and $10 \mathrm{t} \mathrm{ha}^{-1}$. The results indicate that: (i) the maximum damage caused by RTD is the highest (confirming results from correspondence analysis), and (ii) while yield losses caused by SHB tend to increase with attainable yield, those due to RTD tend to decrease, and those due to WB are stable (in proportion). The latter point illustrates the importance of interactions (equation 1 , $Y a \times F_{j}$ terms) between attainable yield and injuries in the yield response equation (equation 1; Table 6): SHB and RTD are involved in these interactions (with opposite final signs), whereas WB is not.

Yield losses caused by rice injuries across tropical Asia. Table 7 lists the results of yield loss computations, considering each injury separately or in combination, assuming a fixed regional level of attainable yield: $\mathrm{Ya}=5.5 \mathrm{tha}^{-1}$. When the injuries assessed in the survey are considered in terms of means, four groups of injuries can be distinguished with respect to the damage they cause: RTD and DH cause undetectable or very low yield losses (below 0.1\%); BLB, NB, and WM cause low damage (below 1\%); SHB, BS, LB, and $\mathrm{WH}$ cause relatively high yield losses (between 1 and 10\%); and WA and WB cause high losses (above 10\%). When medians are considered instead of means, most injuries cause undetectable or negligible yield losses, except SHB, WH, and more importantly, WA and WB.

Consideration of combined injury levels at their mean values - that is to say of a mean injury profile (45) observed in 456 fields surveyed across the region-leads to a computed relative yield loss of $37.2 \%$ using the empirical model (Table 7). If yield losses caused by mean individual injuries were considered independently, an accumulated yield loss of $63.4 \%$ would be obtained. The estimated damage corresponding to combined injuries at their mean levels reflects interactions among injuries in the actual yield response equation (equation $1, F_{k} \times F_{l}$ term; Table $6, \mathrm{~F} 4$ $\times$ F7 interaction), indicating an overall, less-than-additive effect of injuries in their yield-reducing effect. The same calculation based on median injuries, however, would lead to an accumulated damage of $21.5 \%$, which compares to the yield loss computed with a median injury profile $(19.9 \%$, Table 7). Absence of interaction effect in this case is attributable to the small number of injuries considered (SHB, WH, WA, and WB only) and their small numerical (median) values (Table 7).

Yield losses caused by specific injury profiles in given production situations in tropical Asia. Table 8 summarizes the inputs (injury profiles and set Ya values) and outputs (yield losses) corresponding to the third type of scenario, i.e., combinations of production situations and injury profiles. The latter are expressed both in absolute $(\mathrm{Ya}-\mathrm{Y})$ and relative $([\mathrm{Ya}-\mathrm{Y}] / \mathrm{Y}$; $\%$ ) terms in the four scenarios, totaling $n=$ 328 fields (i.e., $71.9 \%$ of the survey sample). These four scenarios can be described as follows: (i) the combination PR $1 \times \mathrm{IN} 1$, which corresponds to fairly high attainable yields $\left(\mathrm{Ya}=5.9 \mathrm{t} \mathrm{ha}^{-1}\right)$, with high SHB, occurrence of RTD, and relatively high $\mathrm{WM}, \mathrm{WH}, \mathrm{WA}$, and $\mathrm{WB}$, is associated with high yield losses: $2.4 \mathrm{t} \mathrm{ha}^{-1}(41.2 \%)$; (ii) the combination PR5 $\times$ IN2, with medium-low attainable yields $\left(\mathrm{Ya}=4.9 \mathrm{t} \mathrm{ha}^{-}\right.$ ${ }^{1}$ ), with high BS, LB, WA, and WB and relatively high WM, is associated with medium yield losses, $1.7 \mathrm{t} \mathrm{ha}^{-1}$, when considered relative to Ya $(35.4 \%)$; (iii) the combination PR6 $\times$ IN2, with relatively high attainable yields $\left(\mathrm{Ya}=5.6 \mathrm{t} \mathrm{ha}^{-1}\right)$ and the same injury profile, is associated with medium yield losses: $1.9 \mathrm{t} \mathrm{ha}^{-1}(33.5 \%)$; and (iv) the combination PR3 $\times$ IN3, with low attainable yields $\left(\mathrm{Ya}=4.7 \mathrm{tha}^{-1}\right)$, with high BS and also SHB, LB, NB, DH, WH, and relatively high WA and $\mathrm{WB}$, is associated with comparatively lower yield losses: $1.2 \mathrm{t} \mathrm{ha}^{-1}(24.5 \%)$.

\section{DISCUSSION}

Methodology used to develop and analyze the rice yield loss data base. Considering yield variation as a response surface to a number of yield-limiting and yield-reducing factors is an approach that has long been advocated by plant pathologists $(49,54)$, but has seldom been used. This article reports an effort to address in a systematic way damage due to an array of rice pests, alone or in combination, under a range of production situations.

The approach to analyze this data base aimed at allowing the analysis of scenarios where yield losses associated with a given injury profile in a given production situation (represented by its attainable yield) are simultaneously considered. The hypothesis used in analyzing these scenarios is that the variation in experimentally measured attainable yield accounts to a large extent for

Table 6. Multiple regression analysis: coefficients, standard error, and probabilities for each variable

\begin{tabular}{lccc}
\hline Variable $^{\mathrm{a}}$ & Coefficient & Standard error & $\boldsymbol{P}(\mathbf{2}$ tails $)$ \\
\hline $\mathrm{Ya}^{\mathrm{b}}$ & +0.807 & 0.007 & $<0.00001$ \\
$\mathrm{~F} 2^{\mathrm{c}}$ & -0.175 & 0.039 & 0.00001 \\
$\mathrm{~F} 4$ & -0.305 & 0.039 & $<0.00001$ \\
$\mathrm{~F} 6$ & +0.212 & 0.091 & 0.019 \\
$\mathrm{~F} 7$ & +0.238 & 0.113 & 0.035 \\
$\mathrm{Ya} \times \mathrm{F} 3$ & -0.044 & 0.007 & $<0.00001$ \\
$\mathrm{Ya} \times \mathrm{F6}$ & -0.079 & 0.016 & $<0.00001$ \\
$\mathrm{Ya} \times \mathrm{F} 7$ & -0.106 & 0.020 & $<0.00001$ \\
$\mathrm{~F} 4 \times \mathrm{F} 7$ & +0.121 & 0.030 & 0.00008 \\
\hline
\end{tabular}

a The regression equation tested is of the form: $Y=a Y a+\Sigma\left(b_{i} F_{i}\right)+\Sigma\left(c_{j} Y a \times F_{j}\right)+\Sigma \Sigma\left(d_{k, l} F_{k} \times F_{l}\right)$, with $R^{2}=0.978, F$ (regression) $=2,269.04$, and $P$ (regression) $<0.00001$.

${ }^{\mathrm{b}} \mathrm{Ya}$ is the attainable yield achieved in each production situation.

c The $F$ 's are factors generated by a normalized principal component analysis on injuries (Table 2).

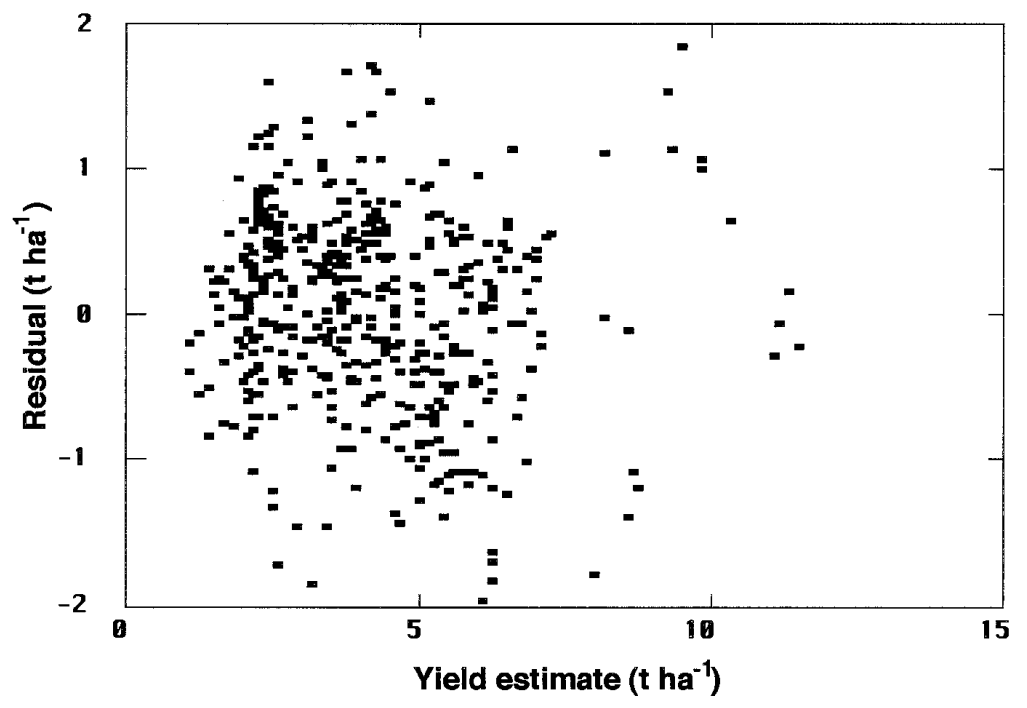

Fig. 2. Plot of residuals of the yield response surface equation generated from the experimental yieldloss data base for lowland rice. The equation was derived from a principal component regression (Table 6), where actual yield varies with attainable yield, injuries, and their interactions. 

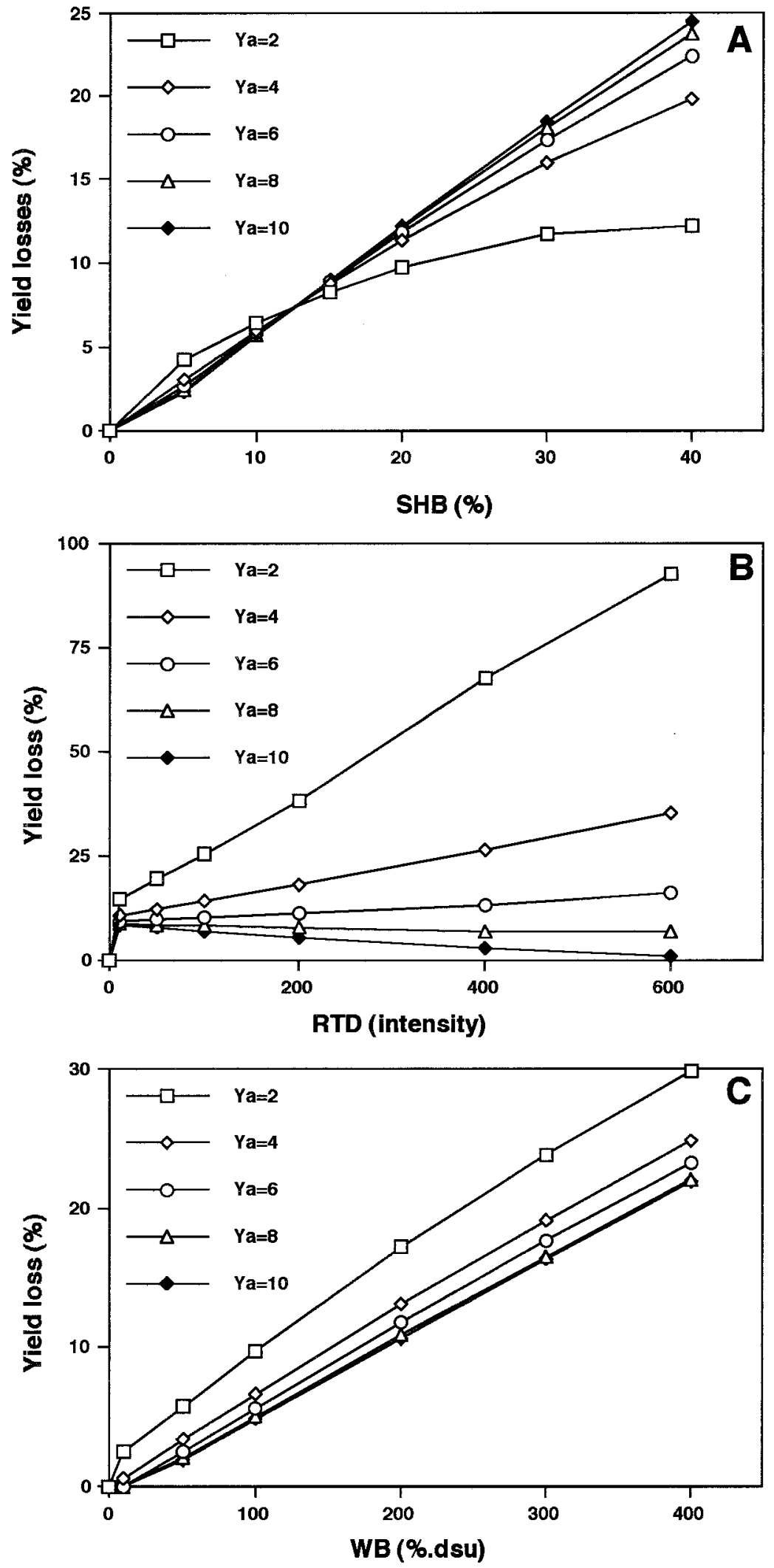

Fig. 3. Variation in relative losses (\%) in response to varying levels of attainable yield and injuries. Five levels of attainable yield (Ya) were considered (2, 4, 6, 8, and $\left.10 \mathrm{tha}^{-1}\right)$, with a range of (A) injury due to sheath blight (SHB), (B) rice tungro disease (RTD), and (C) weed infestation below the rice crop canopy (WB). Each scenario (Ya and injury level) was considered using the principal component regression model shown in Table 6. Units for injuries are listed in Table 2 and explained in the text. variations in patterns of cropping practices and, more broadly, of production situations. Three points justify this simplification and allow us to derive conclusions from the analysis of these scenarios: (i) the production factors that were considered in these experiments do reflect key components that triggered agricultural change in rice production across Asia (14); (ii) attainable yield is only seen as one indicator of production situations; several analyses, in the Philippines, India, and Vietnam, as well as across Asia (45), indicate that the link between production situations and actual yield is very strong; presumably the link between variations of actual and attainable yields is also very strong; (ii) in this analysis of a farmers' fields survey, only a few components of production situations were considered (45); this simplification of production situations into a few elements (patterns of cropping practices and weather types) is congruent with the simplification used here to define production situations in the development of the experimental yield-loss data base.

Each of the experimental components of the data base was designed in such a way that injury-damage relationships would be adequately represented: efforts concentrated on establishing injury treatments that would mimic a spontaneous development in the field and on carefully measuring the crop response. Yield losses caused by individual injuries that are higher than $30 \%$ probably are infrequent in farmers' fields $(24,50,52,55)$. Achieving a wide range of injury levels, from low to extreme, was an important objective of these experiments, in order to allow the analysis of a set of scenarios. The wide range of damage levels covered by this experimental data base is therefore a reflection of its design: injuries were artificially introduced in plots at differing levels, depending on the experiment, and a series of injuries and their combinations were considered.

Plot yields in the experimental data base varied from 2 to $11 \mathrm{t} \mathrm{ha}^{-1}$, a range that extends far beyond that of lowland rice yields assessed in farmers' fields across the region (45).

Relative importance of rice pests. Correspondence analysis (Table 5; Fig. 1) provides a means of ranking rice pests with respect to their importance in terms of the potential losses they may cause. Four groups of injuries can be associated with (i) low to medium yield losses: WM and BLB; (ii) medium to high yield losses: SHB and DH; (iii) high yield losses: BS, $\mathrm{LB}$, and NB; (iv) medium to very high yield losses: WH, WB, and WA. The behavior of RTD is outstanding, being associated only with very high yield losses. RTD therefore represents a fifth group of injury of its own. This categorization is based on yield loss experiments and only refers to potential yield losses-i.e., it refers to yield losses that would occur at a 
range of injury levels, including extreme ones, and it disregards the frequency of occurrence of injuries in farmers' fields.

The empirical yield response surface model (equation 1; Table 6) allowed us first to consider simple scenarios where one injury is addressed at a time and where the variation of percent yield loss with varying levels of injury and of attainable yield is computed. Depending on the injury considered (Fig. 3), different yield loss responses were obtained: with increasing attainable yield, the percent losses increase, decrease, and are stable, in the case of SHB, RTD, and WB, respectively. These injuries differ in their corresponding damage mechanisms: while SHB may be associated with several mechanisms (senescence acceleration, light stealing, and tissue consumption), RTD corresponds to stand reduction, and WB is mainly associated with light stealing (compounded by a reduction of photosynthetic rate and a senescence acceleration if the crop is constrained by a limited supply of water and/or nutrients). The multiple damage mechanisms of SHB may be expected to have greater impact on yield reduction as attainable yield increases; whereas decrease of percent yield loss due to RTD with increasing attainable yield can easily be explained by an increased crop compensation capacity; and light interception caused by WB represents a constant attrition in energy inflow and thus remains proportional in its effects with increasing attainable yield. The different yield loss curves are thus consistent with differing damage mechanisms and support the biological validity of the empirical model used, in addition to statistical tests and residual plot (Fig. 2).

Further quantitative analysis of experimental data in combination with farmers' field survey information provide a more documented and quite different picture of losses caused by rice pests. When an estimate of the mean attainable yield in farmers' fields, $5.5 \mathrm{t} \mathrm{ha}^{-1}$, is considered simultaneously with the mean level of each injury across the region (Table 7), yieldloss estimates for RTD and DH are very low (below $0.1 \%$ ); for BLB, NB, and WM are low (below 1\%); for SHB, BS, LB, and WH are relatively high (below 10\%); and for WA and WB are high (above 10\%). RTD no longer assumes its prominent position because of its rarity in the survey sample. On the contrary, a disease such a sheath blight gains increasing importance in this scenario because of its ubiquity. On the other hand, in farmers' fields, NB seldom reaches the levels attained in the data base experiments and thus does not have the importance one might expect. This second view may appear counterintuitive. It is, however, based on a relatively large sample of farmers' fields in six sites in tropical Asia (45), and the regression model used to derive these calculation does not exhibit any major flaw. One may question, too, the level of attainable yield considered. The actual yield observed in the survey has a mean of 4.12 with a confidence interval $(P=0.05)$ of $0.13 \mathrm{tha}^{-1}$ (45). This is within the range of commonly cited lowland rice yield levels in farmers' fields (14). The estimate of the corresponding attainable yield at about $5.5 \mathrm{t} \mathrm{ha}^{-1}$ seems therefore reasonable. This second reasoning, where both experimental and survey information are combined, gives import to chronic or recurrent injuries that cause moderate damage but are omnipresent. It is important to stress that this reasoning does not imply that sporadic epidemics of rice tungro disease or blast (causing neck and panicle injuries) would not cause considerable losses-they certainly can $(5,26,28)$, but they are infrequent $(45)$.

Consideration of medians further changes this regional picture (e.g., with

Table 7. Relative yield losses (\%) at an attainable rice yield of $5.5 \mathrm{t} \mathrm{ha}^{-1}$ in scenarios of various individual injuries: at their individual mean levels observed in a survey at six sites in tropical $\operatorname{Asia}^{\mathrm{a}}(n=$ 456 farmers' fields), at their individual median levels in this survey, and combined at their mean or median levels

\begin{tabular}{|c|c|c|c|c|}
\hline \multirow[b]{2}{*}{ Injuries } & \multicolumn{2}{|c|}{ Mean survey } & \multicolumn{2}{|c|}{ Median survey } \\
\hline & Levels $^{\mathbf{b}}$ & Losses (\%) & Levels $^{\mathbf{b}}$ & Losses (\%) \\
\hline SHB & 10.0 & 6.1 & 5.0 & 3.1 \\
\hline BLB & 21 & 0.2 & 0 & 0 \\
\hline RTD & 0.4 & 0.0 & 0 & 0 \\
\hline BS & 387 & 5.0 & 13 & 0 \\
\hline LB & 33 & 5.0 & 0 & 0 \\
\hline NB & 1.6 & 0.3 & 0 & 0 \\
\hline WM & 117 & 0.3 & 36 & 0 \\
\hline DH & 2.1 & 0.1 & 0.8 & 0.1 \\
\hline WH & 3.2 & 2.3 & 1.7 & 1.2 \\
\hline WA & 318 & 23.0 & 133 & 10.1 \\
\hline WB & 382 & 21.1 & 133 & 7.0 \\
\hline Combined $^{\mathrm{c}}$ & & 37.2 & & 19.9 \\
\hline
\end{tabular}

${ }^{a}$ Data from (45).

${ }^{\mathrm{b}}$ Injuries are expressed in units given in Table 1.

${ }^{c}$ Yield-loss estimates based on combined levels of injuries at their mean or median levels.

Table 8. Absolute and relative yield losses (\%) due to rice pests in a set of patterns of cropping practices $\times$ injury profiles $(\mathrm{PR} \times \mathrm{IN})$ characterized in a survey at six sites in tropical Asia ${ }^{\mathrm{a}}$

\begin{tabular}{lcccc}
\hline & \multicolumn{4}{c}{ Combinations of injury profile $\left(\mathbf{I N}^{\mathbf{b}}\right)$ by patterns of cropping practices $\left(\mathbf{P R}^{\mathbf{c}}\right)$} \\
\cline { 2 - 5 } Injuries $^{\mathbf{d}}$ & IN1 $\times$ PR1 & IN2 $\times$ PR5 & IN2 $\times$ PR6 & IN3 $\times$ PR3 \\
\hline Injury levels (IN) by & profiles & & & \\
SHB & 12.1 & 6.1 & 6.1 & 9.9 \\
BLB & 0 & 75 & 75 & 0 \\
RTD & 1.35 & 0 & 0 & 0 \\
BS & 7 & 628 & 628 & 727 \\
LB & 0 & 49 & 49 & 79 \\
NB & 0 & 0.9 & 0.9 & 4.7 \\
WM & 161 & 145 & 145 & 36 \\
DH & 1.5 & 1.9 & 1.9 & 3.4 \\
WH & 2.4 & 1.9 & 1.9 & 5.8 \\
WA & 291 & 429 & 429 & 325 \\
WB & 300 & 557 & 557 & 4.7 \\
Yield and losses by IN $\times$ PR combinations & & & 5.9 \\
Ya*e & 5.9 & 4.9 & $1.9 \pm 0.2$ & $1.2 \pm 0.2$ \\
YL & $2.4 \pm 0.3$ & $1.7 \pm 0.2$ & 33.5 & 24.5 \\
YL $(\%)$ & 41.2 & 35.4 & & \\
\hline
\end{tabular}

${ }^{a}$ Data from (45). Only PR $\times$ IN combinations that were represented by more than $n=30$ fields in the survey were considered: IN1 $\times$ PR1: $n=135$; IN2 $\times$ PR5: $n=56$; IN2 $\times$ PR6: $n=32$; IN3 $\times$ PR3: $n$ $=105$ farmers' fields.

b Injury profiles (IN) consist of combinations of injury levels (SHB, BLB, RTD, BS, LB, NB, WM, DH, WH, WA, and WB).

${ }^{c}$ Each PR group refers to patterns of cropping practices characterized from a survey in tropical Asia (45): PR1: transplanted rice, good water management, rice-rice rotation, long fallow, medium pesticide use, medium fertilizer use; PR3: transplanted rice, poor water management, rice-wheat rotation, short fallow, low pesticide use, low fertilizer use; PR5: direct-seeded rice, poor water management, rice-rice rotation, short fallow, medium pesticide use, medium fertilizer use; PR6: direct-seeded rice, medium water management, rice-rice rotation, short fallow, high pesticide use, high fertilizer use.

${ }^{\mathrm{d}}$ Injuries are expressed in units given in Table 1; the mean values in each injury profile characterized in the survey are used.

${ }^{\mathrm{e}}$ Attainable yields were estimated as $\mathrm{Ya}^{*}=$ mean $\mathrm{Y}+1 \times$ (Standard error) for each pattern of cropping practice and are expressed in $\mathrm{tha}^{-1}$.

$\mathrm{f}$ Yield losses $\left(\mathrm{Ya}^{*}-\mathrm{Y}\right)$ are expressed in $\mathrm{tha}^{-1}$. 
respect to brown spot), but to a lesser extent. In that case, computation suggests that only SHB, WH, WA, and WB should be considered significant yield-reducing injuries region-wide (Table 7). From the statistical standpoint, nonnormal distribution frequencies of injuries would encourage one to consider medians rather than means. Field experience, however, suggests that medians across such a large sample would not always properly account for the diverse sites, climate types, and production situations considered in the survey. A series of scenario analyses by production situations was thus undertaken.

When all injuries are considered at their survey mean levels, i.e., when a mean, region-wide injury profile is considered, a mean yield-loss estimate of $37.2 \%$ is computed (Table 7). This figure corresponds to the (unassessed numerically) range reported by Greenland (14) and is well below the commonly cited estimate by Cramer (55.1\%; 7), which Teng et al. (55) considered quite high. Table 7 indicates that injuries interact and that their yield-reducing effects are less than additive, a result often found in studies on yield losses caused by multiple pests on various crops $(17,19,48)$. One important difference in our results from reports by Cramer (7) and Greenland (14) is in the ordering of harmful agents: these authors consider insects to be the most important rice pests, while weeds and pathogens cause similar damage. This study, on the contrary, strongly points to weeds as the most damaging type of harmful agents by far, followed in sequence by pathogens and insects.

Scenario analyses by production situations and injury profiles. Compared with the overall view presented in Table 7 , consideration of specified production (PR) by injury profile (IN) combinations (Table 8) generates a more documented view of the problem of yield-loss assessment, and more generally, of the issue of ranking yield-reducing factors. The outputs of the considered scenarios refer to very different injury profiles, from which it is possible to infer hypotheses on the specific importance of some pests in differing production situations.

The PR $1 \times$ IN1 combination, which prevails in relatively high-input rice-rice rotations of rainy seasons in the humid tropics, illustrates the importance of SHB and RTD, with a background of recurring, chronic problems caused by insects (WM, $\mathrm{WH}$ ) and, probably to a greater extent, weeds (WA, WB). The yield losses in this scenario are quite high. The PR5 $\times$ IN2 and PR6 $\times$ IN2 combinations, which also prevail in the humid tropics of Asia, but where direct seeding predominates and there are frequent water supply problems, in spite of otherwise relatively high input (PR5), or where the rice-rice rotation is extremely fast and input is very high (PR6), highlight the importance of weed infestation (WA and WB) as well as that of BS and LB. In these two scenarios, yield losses can be high and presumably are mainly attributable to weed infestation. The combination PR3 $\times$ IN3 refers to production situations and injury profiles prevailing in the subhumid tropics of tropical Asia (i.e., the rice-wheat system of southern Asia). In these production situations, input-including control of the water supply to the crops-often is very low and environmental constraints are harsh (especially with erratic rainfall patterns). A whole array of injuries contributes to damage in the PR $3 \times$ IN 3 combination, among which BS appears to play a prominent role, in combination with other injuries (SHB, LB, NB, DH, WH).

Rice research priorities in plant protection. Setting priorities for plant protection research in rice can be based on several standpoints. Four of them are briefly discussed below.

Yield attrition due to chronic injuries is commonly underestimated. This is partly due to the fact that yield losses in farmers' fields are virtually undetectable: they are below the precision of any yield estimation methodology (32). The present study derived such estimates from a series of experiments analyzed using a multivariate approach, and their importance becomes apparent, as was suggested by a risk-analytical approach (40). Dead hearts, caused by stem borers and possibly leaf-damaging insects, represented in the present study by whorl maggots, belong to this category. When considering chronic, omnipresent pests that cause a systematic yield attrition across the region, weeds, whether infesting the crop above or below its canopy, obviously represent the first and main constraint.

Another standpoint is that of the sporadic, devastating effects of some injuries. This study shows how devastating rice tungro disease can be, from an experimental standpoint. It fails to show, however, that RTD actually is a key constraint across the region, possibly because of the location of the sites chosen in the survey. A similar reasoning - a potentially devastating damage, mitigated or not, by its frequency of occurrence over time and space-could apply to blast (LB and NB) as well as to $\mathrm{BLB}$, with the appearance of new genotypes of the pathogens that are aggressive to the currently deployed genotypes of the host.

A third standpoint is that of the change of agricultural patterns toward more favorable production situations, i.e., higher attainable yield. Some injuries may become constraints to agricultural change toward higher productivity, and this study points at sheath blight as one of them. When achieving high attainable yields assumes a higher level of priority, so would injuries of this type.

Much has been written on the need to increase rice yield production to meet
Asia's demand by 2015 to 2020 (a yield increase of about $50 \%$ is necessary; 14). Most of this increase will have to be generated by agricultural lowlands already under cultivation. It is likely that a large fraction of rice farmers will not contribute to this increase and will face the same problems they encounter today. The PR $3 \times$ IN3 scenario is characterized by low attainable yields due to insufficient infrastructure (e.g., irrigation systems) and input. It typifies production situations running the risk of being left out of agricultural development. Alleviation of yieldreducing factors in such unfavorable production situations is perhaps one means to improve the well-being of many, and thus it should be seen as a priority. Interestingly, this scenario corresponds to a unique, complex combination of yieldreducing factors and will presumably require a specific approach to pest management.

\section{ACKNOWLEDGMENTS}

This research was partly funded by the French Ministry of Foreign Affairs and by a grant from the Rockefeller Foundation. We are grateful to J. A. Litsinger, A. Barrion, and M. Mabbayad for assistance in experiments involving insects and weeds, to Hans O. Pinnschmidt for sharing with us yield-loss data on rice blast, and to T. W. Mew, M. Hossain, and K. S. Fischer at IRRI and R. W. Herdt at the Rockefeller Foundation for their support in this study.

\section{LITERATURE CITED}

1. Ahn, S. W., and Mukelar, A. 1986. Rice management under upland conditions. Pages 363374 in: Progress in Upland Rice Research. IRRI, Manila, Philippines.

2. Benzécri, J. P. 1973. L'analyse des données. Vol. 2. L'Analyse des Correspondances. Dunod, Paris

3. Boote, K. J., Jones, J. W., Mishoe, J. W., and Berger, R. D. 1983. Coupling pests to crop growth simulators to predict yield reductions. Phytopathology 73:1581-1587.

4. Campbell, C. L., and Madden, L. V. 1990 Introduction to Plant Disease Epidemiology. John Wiley \& Sons, New York.

5. Chancellor, T. C. B., Teng, P. S., and Heong, K. L., eds. 1996. Rice Tungro Disease Epidemiology and Vector Ecology. IRRI Discussion Pap. Ser. 19. Los Baños, Philippines.

6. Chiarappa, L., ed. 1971. Crop loss assessment methods. FAO manual on evaluation and prevention of losses by pests, diseases, and weeds. Comm. Agric. Bureaux, Farnham, England.

7. Cramer, H. H. 1987. Plant Protection and World Food Froduction. PlantzenschutzNachrichten-Bayer.

8. Dagnélie, P. 1973. Théorie et Méthodes Statistiques. Applications Agronomiques. Vol. 2. Presses Agronomiques de Gembloux, Gembloux.

9. Dervin, C. 1988. Comment interpréter les résultats d'une analyse factorielle des correspondances? Institut Technique des Céréales et Fourrages, Paris.

10. De Wit, C. T., and Penning de Vries, F. W. T. 1982. L'analyse des systèmes de production primaires. Pages 275-283 in: La Productivité des Pâturages Sahéliens. F. W. T. Penning de Vries and M. A. Djiteye, eds. Agric. Res. Rep. 918, Pudoc, Wageningen, Netherlands.

11. Draper, N., and Smith, H. 1981. Applied Regression Analysis. 2nd ed. John Wiley \& 
Sons, New York.

12. Du, P. V., Elazegui, F. A., and Savary, S. 1997. A survey of rice constraints in the Mekong delta. Int. Rice Res. Notes 22:43-44.

13. Greenacre, M. J. 1984. Theory and Applications of Correspondence Analysis. Academic Press, London.

14. Greenland, D. J. 1997. The Sustainability of Rice Farming. CABI-IRRI, Wallingford, England.

15. Heinrichs, E. A., Medrano, F. G., and Rapusas, H. R. 1985. Whorl maggot. Pages 23-31 in: Genetic Evaluation for Insect Resistance in Rice. IRRI, Manila, Philippines.

16. James, W. C., Shih, C. S., Hodgson, W. A., and Callbeck, L. C. 1976. Representational errors due to interplot interference in field experiments with late blight of potato $(P$. infestans). Phytopathology 66:695-700.

17. Johnson, K. B. 1990. Assessing multiple pest populations and their effects on crop yield. Pages 203-213 in: Crop Loss Assessment in Rice. IRRI, Los Baños, Philippines.

18. Johnson, K. B., Radcliffe, E. B., and Teng, P. S. 1986. Effects of interacting populations of Alteranaria solani, Verticillium dahliae, and the potato leafhopper (Empoasca fabae) on potato yield. Phytopathology 76:1046-1052.

19. Johnson, K. B., Teng, P. S., and Radcliffe, E. B. 1987. Analysis of potato foliage losses caused by interacting infestations of early blight, verticillium wilt, and potato leafhopper; and the relationship to yield. Z. Pflanzenkrankh. Pflanzenschutz 94:22-33.

20. Karganilla, A. D., Natural, M. P., and Ou, S. H. 1973. A comparative study of culture media for Xanthomonas oryzae. Philipp. Agric. 57:141-152.

21. Kauffman, H. E., Reddy, A. P. K., Hsieh, S. P. Y., and Merca, S. D. 1973. An improved technique for evaluating resistance of rice varieties to Xanthomonas oryzae. Plant Dis. Rep. 57:537-541.

22. Lames, F. C., and McCulloch, C. E. 1990. Multivariate analysis in ecology and systematics: Panacea or Pandora's box? Annu. Rev. Ecol. Syst. 21:129-166.

23. Ling, K. C. 1974. A cage method for studying experimental epidemiology of rice tungro disease. Philipp. Phytopathol. 10:31-41.

24. Litsinger, J. A. 1992. Crop loss assessment in rice. Pages 1-65 in: Rice Insects: Management Strategies. E. A. Heinrichs and T. A. Miller, eds. Springer-Verlag, New York.

25. Madden, L. V., and Nutter, F. W., Jr. 1995. Modeling crop losses at the field scale. Can. J. Plant Pathol. 17:124-135.

26. Mew, T. W. 1991. Disease management in rice. Pages 279-299 in: CRC Handbook of Pest Management in Agriculture. 2nd ed. Vol. III. D. Pimentel and A. A. Hanson, eds. CRC Press, Boca Raton, FL.

27. Oerke, E. C., Dehne, H. W., Schönbeck, F., and Weber, A. 1994. Crop Production and Crop Protection: Estimated Losses in Major Food and Cash Crops. Elsevier, Amsterdam.

28. Ou, S. H. 1987. Rice Diseases. 2nd ed. C.A.B. International, Farnham Royal, Slough, England.
29. Parlevliet, J. E., and Van Ommeren, A. 1975. Partial resistance of barley to leaf rust, Puccinia hordei. II. Relationship between field trials, microplot tests, and latent period. Euphytica 24:293-303

30. Pinnschmidt, H. O., Batchelor, W. D., and Teng, P. S. 1995. Simulation of multiple species pest damage in rice using CERES-rice. Agric. Syst. 48:193-222.

31. Pinnschmidt, H. O., Teng, P. S., and Yong, L. 1994. Methodology for quantifying rice yield effects of blast. Pages 381-408 in: Rice Blast Disease. R. S. Zeigler, P. S. Leong, and P. S. Teng, eds. IRRI-CABI, Wallingford, England.

32. Poate, D. 1988. A review of methods for measuring crop production from small-holder producers. Exp. Agric. 24:1-14.

33. Pongprasert, S., Gunsee, S., Suwanabutr, S., Chinoros, P., and Weerapat, P. 1975. Screening for varietal resistance to major insect pests of rice in Thailand. Rice Entomol. Newsl. 2:18-21.

34. Porkess, R. 1988. Dictionary of Statistics. Collins, London

35. Rabbinge, R. 1993. The ecological background of food production. Pages 2-29 in: Crop Protection and Sustainable Agriculture. Ciba Foundation Symposium 77. D. J. Chadwick and J. Marsh, eds. John Wiley \& Sons, Chichester, England

36. Rossing, W. A. H. 1991. Simulation of damage in winter wheat caused by the grain aphid Sitobion avenae. 3. Calculation of damage at various attainable yield levels. Neth. J. Plant Pathol. 97:87-103.

37. Savary, S., Castilla, N. P., Elazegui, F. A., McLaren, C. G., Ynalvez, M. A., and Teng, P. S. 1995. Direct and indirect effects of nitrogen supply and disease source structure on rice sheath blight spread. Phytopathology 85:959-965.

38. Savary, S., Elazegui, F. A., Moody, K., and Teng, P. S. 1994. Characterization of rice cropping practices and multiple pest systems in the Philippines. Agric. Syst. 46:385-408.

39. Savary, S., Elazegui, F. A., Pinnschmidt, H. O., Castilla, N. P., and Teng, P. S. 1997. A New Approach to Quantify Crop Losses due to Rice Pests in Varying Production Situations. IRRI Discussion Pap. Ser. 20. IRRI, Manila, Philippines.

40. Savary, S., Elazegui, F. A., Pinnschmidt, H. O., and Teng, P. S. 1996. Characterization of rice pest constraints in Asia: An empirical approach. Pages 83-98 in: Application of Systems Approaches at the Field Level. Vol. 1. M. J. Kropff, P. S. Teng, P. K. Aggarwal, J. Bouma, B. A. M. Bouman, J. W. Jones, and H. H. Van Laar, eds. Kluwer Scientific Publishers, Dordrecht, Netherlands.

41. Savary, S., Elazegui, F. A., and Teng, P. S. 1996. A survey portfolio for the characterization of rice pest constraints. IRRI Discussion Pap. Ser. 18. IRRI, Manila, Philippines.

42. Savary, S., Elazegui, F. A., and Teng, P. S. 1998. Assessing the representativeness of data on yield losses due to rice diseases in tropical Asia. Plant Dis. 82:705-709.

43. Savary, S., Madden, L. V., Zadoks, J. C., and
Klein-Gebbinck, H. W. 1995. Use of categorical information and correspondence analysis in plant disease epidemiology. Adv. Bot. Res. Incorporating Adv. Plant Pathol. 21:213-240.

44. Savary, S., Srivastava, R. K., Singh, H. M., and Elazegui, F. A. 1997. A characterization of rice pests and quantification of yield losses in the rice-wheat system of India. Crop Prot 16:387-398.

45. Savary, S., Willocquet, L., Elazegui, F. A., Teng, P. S., Du, P. V., Zhu, D., Tang, Q., Huang, S., Lin, X., Singh, H. M., and Srivastava, R. K. 1999. Rice pest constraints in tropical Asia: Characterization of injury profiles in relation to production situations. Plant Dis. 84:341-356.

46. Savary, S., and Zadoks, J. C. 1989. Analysis of components in the host-parasite interaction of ground rust. II. Measurement of intermediate resistance using a microplot trial. Oléagineux 44:222-224.

47. Savary, S., and Zadoks, J. C. 1992. Analysis of crop loss in the multiple pathosystem groundnut-rust-leaf spot. I. Six experiments. Crop Prot. 11:99-109.

48. Savary, S., and Zadoks, J. C. 1992. Analysis of crop loss in the multiple pathosystem groundnut-rust-leaf spot. II. Study of the interaction between diseases and crop intensification in factorial designs. Crop Prot. 11:110 120.

49. Shane, W. W., and Teng, P. S. 1987. Generating the data base for disease-loss modeling. Pages 82-89 in: Crop Loss Assessment and Management. P. S. Teng, ed. American Phytopathological Society, St Paul, MN.

50. Shepard, B. M., Khan, Z. R., Pathak, M. D. and Heinrichs, E. A. 1991. Management of rice pests in Asia. Pages 255-278 in: CRC Handbook of Pest Management in Agriculture. 2nd ed. Vol. III. D. Pimentel and A. A Hanson, eds. CRC Press, Boca Raton, FL.

51. Teng, P. S., ed. 1987. Crop Loss Assessment and Pest Management. American Phytopathological Society, St. Paul, MN.

52. Teng, P. S. 1990. Integrated Pest Management in Rice. An Analysis of the Status Quo With Recommendation for Action. Rep. USAID Pestic. Pest Manage. Proj.

53. Teng, P. S. 1994. Integrated pest management in rice. Exp. Agric. 30:115-117.

54. Teng, P. S., and Gaunt, R. E. 1980. Modelling systems of disease and yield loss in cereals. Agric. Syst. 6:131-154

55. Teng, P. S., Torres, C. Q., Nuque, F. L., and Calvero, S. B. 1990. Current knowledge on crop losses in tropical rice. Pages 39-54 in: Crop Loss Assessment in Rice. IRRI, Los Baños, Philippines.

56. Van Ittersum, M. K., and Rabbinge, R. 1997. Ecology for analysis and quantification of agricultural input-output combinations. Field Crops Res. 52:197-208

57. Zadoks, J. C. 1985 . On the conceptual basis of crop loss assessment: The threshold theory. Annu. Rev. Phytopathol. 23:455-473.

58. Zadoks, J. C., and Schein, R. D. 1979. Epidemiology and Plant Disease Management Oxford University Press, New York. 